\title{
A Box Model for Representing Estuarine Physical Processes in Earth System Models
}

\author{
Qiang Sun ${ }^{1 *}$, Michael M. Whitney ${ }^{1}$, Frank O. Bryan ${ }^{2}$, and Yu-heng Tseng ${ }^{2}$
}




\section{Abstract:}

12 Appropriately treating riverine freshwater discharge into the oceans in Earth system models is a 13 challenging problem. Commonly, the river runoff is discharged into the ocean models with zero 14 salinity and arbitrarily distributed either horizontally or vertically over several grid cells. Those approaches entirely neglect estuarine physical processes that modify river inputs before they reach the open ocean. In order to realistically represent riverine freshwater inputs in Earth system

17 models, a physically based Estuary Box Model (EBM) is developed to parameterize the mixing 18 processes in estuaries. The EBM represents the estuary exchange circulation with a two-layer 19 box structure. It takes as input the river volume flux from the land surface model and the 20 subsurface salinity at the estuary mouth from the ocean model. It delivers the estuarine outflow 21 salinity and net volume flux into and out of the estuary to the ocean model. An offline test of the

22 EBM forced with observed conditions for the Columbia River system shows good agreement 23 with observations of outflow salinity and high-resolution simulations of the exchange flow 24 volume flux. To illustrate the practicality of use of the EBM in an Earth system model, the EBM 25 is implemented for all coastal grid cells with river runoff in the Community Earth System Model 26 (CESM). Compared to the standard version of CESM, which treats runoff as an augmentation to 27 precipitation, the EBM increases sea surface salinity and reduces stratification near river mouths. 28 The EBM also leads to significant regional and remote changes in CESM ocean surface salinities. 


\section{Introduction}

32 Rivers deliver an annual average of $1.25 \mathrm{~Sv}\left(1 \mathrm{~Sv}=1 \times 10^{6} \mathrm{~m}^{3} \mathrm{~s}^{-1}\right)$ of freshwater to the ocean

33 (Durack, 2015). These inputs, however, have much larger impacts on oceanic dynamics than 34 would be guessed based on their volume flux alone. Riverine freshwater lowers surface salinity 35 and introduces stratification that can reduce mixed layer thickness, modify currents, and 36 influence air-sea interaction. Coles et. al. (2013) show that the Amazon River freshwater has

37 pathways into the western tropical and subtropical gyres of the North Atlantic. In the Bay of 38 Bengal, the summer monsoon induced riverine discharge can inhibit the air-sea heat exchange by 39 decreasing the Sea Surface Salinity (SSS) to build a barrier layer (Vinayachandran, et al., 2002). 40 Such impacts on ocean salinities and stratification depend on how riverine freshwater initially 41 enters the ocean (Hordoir, et al., 2008). In nature, estuaries transform river inputs before they 42 enter the ocean. Tides and other processes (e.g. winds) generate shear-driven mixing and internal 43 wave breaking entrains saltwater into the fresher layer (Dyer, 1998). This mixing and 44 entrainment drives an estuarine exchange flow (or gravitational circulation) that draws saltwater 45 into estuaries; the saltwater ultimately exits along with riverine freshwater as a mixed (non-zero 46 salinity) outflow to the coastal ocean (e.g. MacCready and Geyer, 2010). Estuaries and their 47 mixing processes have spatial scales below that which can be explicitly represented in Earth 48 system models (ESMs) with horizontal resolutions typically $100 \mathrm{~km}$ or coarser. This study 49 develops and applies an Estuary Box Model (EBM) to represent estuarine processes in ESMs. It 50 provides a physically-based method for introducing riverine freshwater to the model ocean 51 without significantly increasing computational time. 


\section{Background}

54 In ESMs the riverine discharge is usually introduced into the ocean component with zero salinity;

55 implicitly neglecting any estuary mixing or exchange. In addition, instead of applying the

56 freshwater inflow as a horizontal flux entering through the coastal boundary, the riverine

57 freshwater is often applied to the ocean surface as a vertical flux of "augmented precipitation"

58 over a specified ocean region (often hundreds of kilometers wide) surrounding the actual river

59 mouth (Griffies, et al., 2005 and Tseng, et al., 2016). Some models such as the Community Earth

60 System Model (CESM) employ the virtual salt flux (VSF) formulation that handles river inputs

61 (and precipitation) by removing salt from the ocean surface instead of adding freshwater volume.

62 The VSF for rivers is calculated by multiplying the freshwater volume flux with a reference

63 salinity that is usually taken as a global constant (e.g. 34.7 PSU in the CESM) in order to assure

64 global salt conservation. Yin, et al. (2010), and Tseng, et al. (2016) show the limitations of the

65 global reference salinity and use a local reference salinity instead. These studies also distribute

66 the riverine freshwater vertically over several layers or enhance horizontal mixing at river

67 mouths to diffuse the freshwater horizontally. The Tseng, et al. (2016) sensitivity study shows

68 that ocean model results strongly depend on the river input methods and finds that CESM can be

69 run successfully without the large spreading regions typically used. All these methods omit the

70 important natural physical processes that fresh riverine runoff will be pre-mixed with saltier

71 oceanic water within estuaries, rather than discharged into ocean with zero salinity.

72 Garvine and Whitney (2006) made a first attempt to parameterize the estuarine mixing processes

73 for climate models. They built an estuary box model based on the potential energy anomaly

74 concept introduced by Simpson et. al. (1990) and compared results to observations for the

75 Delaware Bay. Rice et. al. (2008) added a two-layer formulation to this box model. Hordoir, et. 
al. (2008) implemented a shelf box model based on the idea of potential energy anomaly (in

77 NEMO, Nucleus for European Modelling of the Ocean) that reproduced the coastal overturning

78 on the Mekong shelf for both upwelling- and downwelling-favorable winds. Herzfeld (2015)

79 developed a numerical method to introduce the riverine freshwater input and include upper and

80 lower layer exchange by considering estuary salt wedge adjustment that is most appropriate for

81 highly stratified estuaries with weak tides and/or strong river discharge. MacCready and Geyer

82 (2010) summarize up-to-date estuarine mixing parameterizations in their review paper. Their

83 review provides the theoretical basis and parameterizations that support the development of the

84 new EBM that represents the essential influence of estuarine exchange flow. In this study we

85 focus on the formulation of a new EBM and its calibration and validation against observations

86 for a well-observed estuary system - the Columbia River. We additionally demonstrate the

87 practicality of its application in ESMs, and make an initial assessment of its impact in a global

88 simulation with the CESM. A more thorough analysis of impacts on the global climate, the 89 sensitivity to parameter choices within the EBM, and broader comparisons with observations 90 will be addressed in subsequent studies.

\section{3. Estuary Box Model development}

\section{3.1. Configuration}

94 The EBM is a two-layer rectangular box with constant width (W), constant total depth $(\mathrm{H})$, and

95 time-varying length (L) (Figure 1). Each layer has a constant thickness (h and H-h for the lower 96 and upper layers, respectively) and a vertically uniform (but horizontally varying) salinity and

97 density; thus, the estuary model water column is vertically piecewise constant. The salinity and 98 density are allowed to vary horizontally to better represent horizontal gradients in salinities at the 
mouth boundary; the domain including the EBM and connecting ocean model has a horizontally

100 piecewise continuous salinity solution. $\mathrm{L}$ is the landward extent of the lower-layer saltwater

101 intrusion that adjusts to forcing conditions; this estuary length adjustment allows for

102 simplifications later and better represents estuarine dynamics (MacCready and Geyer, 2010). The

$103 \mathrm{X}$-axis originates at the mouth and is positive towards the ocean. The $\mathrm{z}$-axis is defined positive

104 upward from the bottom. Riverine freshwater discharge $\left(Q_{R}\right)$ enters through the estuary head.

105 Oceanic saltwater flows into the EBM through the mouth lower layer $\left(\mathrm{Q}_{\mathrm{LM}}\right)$; note that $\mathrm{Q}_{\mathrm{LM}}$ is 106 negative. Tidal pumping (e.g. MacCready, 2007) can drive a net horizontal salt flux into the 107 mouth upper layer. The tidal pumping results from differences in salt advection during flood and 108 ebb, which can be modeled as a diffusive flux in subtidal analysis (averaged over tidal 109 variations). The upper and lower layers in the EBM communicate via vertical tidal mixing and 110 by the upward advection (associated with estuary exchange flow). Mixed estuarine water flows 111 to the coastal ocean though the mouth upper layer $\left(\mathrm{Q}_{\mathrm{UM}}\right)$.

\section{3.2. Continuous governing equations}

113 The fundamental governing equations are tidally-averaged (subtidal), laterally-averaged, and 114 steady-state. Estuaries experience non-steady-state dynamics over several time scales, but the 115 steady-state dynamics assumed here are expected to provide a reasonable representation of the 116 estuaries over monthly time scales. The volume balance, i.e. the incompressible continuity (Eqn. 117 1), involves the along-estuary and vertical velocities ( $u$ and $w)$.

$$
\frac{\partial \mathrm{u}}{\partial \mathrm{x}}+\frac{\partial \mathrm{w}}{\partial \mathrm{z}}=0 \quad \text { Eqn. } 1
$$

118 The salinity balance (Eqn. 2) includes advection and diffusion with horizontal and vertical eddy 119 diffusivities $\left(\mathrm{K}_{\mathrm{H}}\right.$ and $\left.\mathrm{K}_{\mathrm{V}}\right)$. 


$$
\frac{\partial(\mathrm{uS})}{\partial \mathrm{x}}+\frac{\partial(\mathrm{wS})}{\partial \mathrm{z}}=\frac{\partial}{\partial \mathrm{x}}\left(\mathrm{K}_{\mathrm{H}} \frac{\partial \mathrm{S}}{\partial \mathrm{x}}\right)+\frac{\partial}{\partial \mathrm{z}}\left(\mathrm{K}_{\mathrm{V}} \frac{\partial \mathrm{S}}{\partial \mathrm{z}}\right)
$$

120 A linear equation of state (Eqn. 3) is used to calculate density from salinity, where $\rho_{0}$ is $1000 \mathrm{~kg}$ $121 \mathrm{~m}^{-3}$ and $\beta$ is $7.7 \times 10^{-4} \mathrm{PSU}^{-1}$ (MacCready, 1999).

$$
\rho=\rho_{0}(1+\beta S)
$$

122 Converting the salinity balance (Eqn. 2) into density balance and multiplying it by gz yield the 123 potential energy equation (Eqn. 4), where the gravitational potential energy density (PE) is $\rho g z$. $\frac{\partial(\mathrm{uPE})}{\partial \mathrm{x}}+\frac{\partial(\mathrm{wPE})}{\partial \mathrm{z}}=\frac{\partial}{\partial \mathrm{x}}\left[\mathrm{K}_{\mathrm{H}} \frac{\partial(\mathrm{PE})}{\partial \mathrm{x}}\right]+\frac{\partial}{\partial \mathrm{z}}\left[\mathrm{K}_{\mathrm{V}} \frac{\partial(\mathrm{PE})}{\partial \mathrm{z}}\right]-\mathrm{K}_{\mathrm{v}} \mathrm{g} \frac{\partial \rho}{\partial \mathrm{z}}-\mathrm{g} \frac{\partial \mathrm{K}_{\mathrm{v}} \rho}{\partial \mathrm{z}}+\mathrm{wg} \rho$ Eqn. 4

124 The vertical boundary conditions are no-normal-flow through the surface and flat bottom $(\mathrm{w}=0)$

125 and no density sinks or sources $(\mathrm{d} \rho / \mathrm{dz}=0)$. Freshwater fluxes from precipitation and 126 evaporation are neglected within the estuary as small relative to the river inputs. In the following 127 sections, the continuous governing equations are integrated over the estuary domain and 128 parameterizations are applied where required.

\subsection{Estuary-integrated volume and density balances}

130 Vertically and horizontally integrating the continuous volume balance (Eqn. 1) over the entire 131 estuary box domain yields an estuary integrated balance between the river inflow, lower-layer 132 inflow, and upper-layer outflow at the mouth (Eqn. 5); $Q_{U M}$ and $Q_{R}$ are positive and $Q_{L M}$ is 133 negative.

$$
\mathbf{Q}_{\mathrm{UM}}+\mathbf{Q}_{\mathrm{LM}}-\mathbf{Q}_{\mathrm{R}}=\mathbf{0}
$$

134 After vertically integrating the continuous salinity equation (Eqn. 2) the vertical advection and 135 vertical diffusion terms become zero (because of vertical boundary conditions). Subsequent 136 horizontal integration (of the equivalent density equation) yields an estuary-integrated balance 137 (Eqn. 6) among mass fluxes associated with subtidal flow and horizontal diffusion through the 
mouth upper-layer (associated with tidal pumping), and it is assumed there is no diffusion through the other boundaries.

$$
\rho_{\mathrm{LM}} \mathrm{Q}_{\mathrm{LM}}+\rho_{\mathrm{UM}} \mathrm{Q}_{\mathrm{UM}}-\rho_{\mathrm{R}} \mathrm{Q}_{\mathrm{R}}=\left(\rho_{\mathrm{LM}}-\rho_{\mathrm{UM}}\right) \mathrm{a}_{0} \mathrm{a}_{\mathrm{t}} \frac{\mathrm{Q}_{\mathrm{Ut}}}{2} \quad \text { Eqn. } 6
$$

140 The tidal pumping term is based on Stommel and Farmer (1952) and MacCready (2007) and 141 derived in the Appendix. $\mathrm{Q}_{\mathrm{Ut}}$ is defined as positive and is the average tidal volume flux during 142 half a tidal cycle, with $\mathrm{Q}_{\mathrm{Ut}}=2 \mathrm{~W}(\mathrm{H}-\mathrm{h}) \mathrm{u}_{\mathrm{t}} / \pi$ (as in Eqn. A2) where $\mathrm{u}_{\mathrm{t}}$ is the tidal current 143 amplitude. The geometric coefficient $\mathrm{a}_{\mathrm{t}}$ (Eqn. A10 and Eqn. A11) represents the fraction of tidal 144 volume exchange in which the saltier oceanic water replaces estuarine water. MacCready (2007) 145 found that the horizontal diffusion at the estuarine mouth might be overestimated by using this 146 approach, so a coefficient $\mathrm{a}_{0}$ is included as a free parameter. Note that $\rho_{\mathrm{LM}}\left(\mathrm{S}_{\mathrm{LM}}\right)$ is used to 147 represent the density (salinity) entering from outside the estuary. Also note that $\rho_{\mathrm{UM}}$ represents 148 upper-layer conditions at the estuary mouth open boundary and is greater than or equal to the 149 upper layer-averaged density within the estuary.

\subsection{Estuary-integrated potential energy balance}

151 Vertically and horizontally integrating the continuous PE equation (Eqn. 4) and multiplying by 152 the estuary width yields the estuary-integrated PE balance (Eqn. 7).

$$
\begin{aligned}
\frac{1}{2} g \rho_{\mathrm{LM}} \mathrm{Q}_{\mathrm{LM}} \mathrm{h}+ & \frac{1}{2} \mathrm{~g}\left(\rho_{\mathrm{UM}} \mathrm{Q}_{\mathrm{UM}}-\rho_{\mathrm{R}} \mathrm{Q}_{\mathrm{R}}\right)(\mathrm{H}+\mathrm{h}) \\
& =\frac{1}{4} \mathrm{a}_{0} \mathrm{a}_{\mathrm{t}} \mathrm{g}\left(\rho_{\mathrm{LM}}-\rho_{\mathrm{UM}}\right) \mathrm{Q}_{\mathrm{Ut}}(\mathrm{H}+\mathrm{h}) \\
& +\mathrm{K}_{\mathrm{V}} \mathrm{gW} \int_{-\mathrm{L}}^{0}\left[\rho_{\mathrm{L}}(\mathrm{x})-\rho_{\mathrm{U}}(\mathrm{x})\right] \mathrm{dx}+\mathrm{W} \int_{-\mathrm{L}}^{0} \int_{0}^{\mathrm{H}} \text { wg } \rho \mathrm{dzdx} \quad \text { Eqn. } 7
\end{aligned}
$$

153 The terms on the left-hand side represent advection of PE due to horizontal fluxes into or out of 154 the estuary. The first term on the right-hand side of Eqn. 7 is upper-layer integrated horizontal 155 diffusion at the mouth (tidal pumping), which is parameterized as in the density balance (Eqn. 6). 
156 The next term is from the vertical diffusion of $\mathrm{PE}$ and has been written assuming $\mathrm{K}_{\mathrm{V}}$ is vertically

157 uniform. The estuary-integrated vertical diffusion terms are non-zero because of the $\mathrm{z}$ 158 dependence in the second, third and fourth terms on the right-hand side of the continuous PE 159 equation (Eqn. 4). The vertical diffusion increases the potential energy in the water column, so it 160 has the positive sign. The integrals for the mass lifting term, the final term in Eqn. 7, are 161 evaluated in next section.

\subsection{Vertical velocity, density distribution, and estuary length}

163 It is assumed that the vertical velocity $\mathrm{w}$ in the estuary box is independent of $\mathrm{x}$. The $\mathrm{w}$ vertical 164 profile is approximated by a vertically piecewise linear function (Eqn. 8) with a maximal 165 positive (upward) value $\mathrm{w}_{\mathrm{i}}$ at the layer interface and zeros at the surface and bottom.

$$
\mathrm{w}(\mathrm{z})= \begin{cases}\mathrm{w}_{\mathrm{i}} \frac{\mathrm{H}-\mathrm{z}}{\mathrm{H}-\mathrm{h}} & \mathrm{h}<\mathrm{z} \leq H \\ \mathrm{w}_{\mathrm{i}} \frac{\mathrm{z}}{\mathrm{h}} & 0 \leq \mathrm{z} \leq \mathrm{h}\end{cases}
$$

166 Because of the steady-state volume balance, vertical volume flux exiting the lower layer through 167 the layer interface $\left(w_{i} L W\right)$ must equal $-Q_{L M}$. By substituting $w_{i}=-Q_{L M} /(L W)$ and integrating 168 wg $\rho$ over the EBM, the (positive) lifting term in the PE balance (Eqn. 7) is solved in Eqn. 9.

$$
\int_{-\mathrm{L}}^{0} \int_{0}^{\mathrm{H}} \operatorname{wg} \rho \mathrm{dz} d \mathrm{x}=-\frac{1}{2} \mathrm{~g} \frac{\mathrm{Q}_{\mathrm{LM}}}{\mathrm{LW}}\left[(\mathrm{H}-\mathrm{h}) \int_{-\mathrm{L}}^{0} \rho_{\mathrm{U}}(\mathrm{x}) \mathrm{dx}+\mathrm{h} \int_{-\mathrm{L}}^{0} \rho_{\mathrm{L}}(\mathrm{x}) \mathrm{dx}\right] \quad \text { Eqn. } 9
$$

169 A linear density distribution (in the x-direction) with a constant layer density difference is 170 employed in the exchange-dominated solution of MacCready (1999) and other studies (e.g. 171 Huijts, et al., 2009). Observations also suggest the linear approximation is appropriate (Garvine, 172 et al., 1992). Consequently, the horizontal density distribution is approximated by linear 173 functions in each EBM layer (Eqn. 10). 


$$
\begin{aligned}
& \rho_{\mathrm{U}}(\mathrm{x})=\left\{\begin{array}{ll}
\frac{\rho_{\mathrm{LM}}-\rho_{\mathrm{R}}}{\mathrm{L}} \mathrm{x}+\rho_{\mathrm{UM}} & -\Delta \mathrm{x}<x \leq 0 \\
\rho_{\mathrm{R}} & -\mathrm{L} \leq \mathrm{x} \leq-\Delta \mathrm{x}
\end{array} \text { with } \Delta \mathrm{x}=\frac{\rho_{\mathrm{UM}}-\rho_{\mathrm{R}}}{\rho_{\mathrm{LM}}-\rho_{\mathrm{R}}} \mathrm{L}\right. \\
& \rho_{\mathrm{L}}(\mathrm{x})=\frac{\rho_{\mathrm{LM}}-\rho_{\mathrm{R}}}{\mathrm{L}} \mathrm{x}+\rho_{\mathrm{LM}} \quad-\mathrm{L} \leq \mathrm{x} \leq 0
\end{aligned}
$$

174 The density distribution is horizontally piecewise continuous with ocean-side salinities at the 175 mouth; there the upper and lower layer densities reach $\rho_{\mathrm{UM}}$ and $\rho_{\mathrm{LM}}$, respectively. The layer 176 density difference is constant except in the segment from $\Delta \mathrm{x}$ (where the upper-layer starts to 177 deviate from 0 PSU and $\rho_{R}$ ) to the head of EBM (where the lower-layer reaches 0 PSU and $\rho_{R}$ ) 178 where layer density difference linearly decreases to zero. From these approximations, the density 179 integrals in (Eqn. 7 and Eqn. 9) can be solved analytically (Eqn. 11).

$$
\begin{aligned}
& \int_{-L}^{0} \rho_{\mathrm{U}}(\mathrm{x}) \mathrm{dx}=\frac{1}{2} \frac{\rho_{\mathrm{UM}}^{2}-\rho_{\mathrm{R}}^{2}}{\rho_{\mathrm{LM}}-\rho_{\mathrm{R}}} \mathrm{L}+\frac{\left(\rho_{\mathrm{LM}}-\rho_{\mathrm{UM}}\right) \rho_{\mathrm{R}}}{\rho_{\mathrm{LM}}-\rho_{\mathrm{R}}} \mathrm{L} \\
& \int_{-\mathrm{L}}^{0} \rho_{\mathrm{L}}(\mathrm{x}) \mathrm{dx}=\frac{1}{2}\left(\rho_{\mathrm{LM}}+\rho_{\mathrm{R}}\right) \mathrm{L}
\end{aligned}
$$

Eqn. 11

180 MacCready and Geyer (2010) provide the length scale (L) of the estuary salinity intrusion in 181 exchange-dominated estuaries (Eqn. 12).

$$
\mathrm{L}=0.024 \mathrm{a}_{1}\left(\frac{\mathrm{WHc}^{4}}{\mathrm{Q}_{\mathrm{R}} \mathrm{Sc}^{2}}\right)^{1 / 3} \frac{\mathrm{H}^{2}}{\mathrm{~K}_{\mathrm{V}}} \text { with } \mathrm{c}=\sqrt{\mathrm{g} \beta \mathrm{S}_{\mathrm{LM}} \mathrm{H}}
$$

182 In this equation, $\mathrm{a}_{1}$ is an adjustment coefficient, $\mathrm{c}$ is an upper bound for the internal wave speed, and Sc is Schmidt Number (Sc=2.2 for this application). The Schmidt Number may vary from 184 estuary to estuary in nature, but the value chosen here is commonly used for estuarine studies. 185 The underlying principle is the salinity intrusion has adjusted to river discharge and mixing conditions (represented by $\mathrm{K}_{\mathrm{V}}$ ). Applying this fully-adjusted length scale is consistent with the 

derived below). Therefore, it reduces the number of parameters required by the EBM.

$$
\begin{aligned}
\frac{1}{2} g \rho_{\mathrm{LM}} Q_{\mathrm{LM}} \mathrm{h}+ & \frac{1}{2} \mathrm{~g}\left(\rho_{\mathrm{UM}} \mathrm{Q}_{\mathrm{UM}}-\rho_{\mathrm{R}} \mathrm{Q}_{\mathrm{R}}\right)(\mathrm{H}+\mathrm{h}) \\
= & \frac{1}{4} \mathrm{a}_{0} \mathrm{a}_{\mathrm{t}} \mathrm{g}\left(\rho_{\mathrm{LM}}-\rho_{\mathrm{UM}}\right) \mathrm{Q}_{\mathrm{Ut}}(\mathrm{H}+\mathrm{h}) \\
& +0.012 \mathrm{a}_{1}\left(\frac{\mathrm{WHc}}{\mathrm{Q}_{\mathrm{R}} \mathrm{Sc}^{2}}\right)^{1 / 3} \mathrm{~g}\left(\rho_{\mathrm{LM}}-\rho_{\mathrm{UM}}\right) \frac{\left(\rho_{\mathrm{LM}}+\rho_{\mathrm{UM}}-2 \rho_{\mathrm{R}}\right)}{\rho_{\mathrm{LM}}-\rho_{\mathrm{R}}} \mathrm{WH}^{2} \\
& -\frac{1}{4} \mathrm{~g} \frac{(\mathrm{H}-\mathrm{h})\left(\rho_{\mathrm{UM}}^{2}+2 \rho_{\mathrm{LM}} \rho_{\mathrm{R}}-2 \rho_{\mathrm{UM}} \rho_{\mathrm{R}}\right)-\mathrm{H} \rho_{\mathrm{R}}^{2}+\mathrm{h} \rho_{\mathrm{LM}}^{2}}{\rho_{\mathrm{LM}}-\rho_{\mathrm{R}}} \mathrm{Q}_{\mathrm{LM}}
\end{aligned}
$$

The PE balance depends on fluxes and densities at the mouth and head, estuary width, layer thicknesses and total depth, the geometric coefficient for tidal pumping $\left(a_{t}\right.$ is set in Eqn. A10 or Eqn. A11) and two free parameters $\left(\mathrm{a}_{0}\right.$ and $\left.\mathrm{a}_{1}\right)$ that can be used to tune horizontal diffusion and vertical mixing strength for a given estuary. The left-hand side of the Eqn. 13 represents the PE fluxes directly associated with horizontal advection through the head and mouth, while the righthand side includes the contributions of tidal pumping through the mouth, estuarine mixing, and upwelling associated with estuary exchange flow.

\subsection{Dimensional solution}

The steady-state volume, density, and potential energy layer integrated balances (Eqn. 5, Eqn. 6, and Eqn. 13) constitute a system of nonlinear equations to solve the three unknowns $\mathrm{Q}_{\mathrm{LM}}, \mathrm{Q}_{\mathrm{UM}}$, and $\rho_{\mathrm{UM}} . \mathrm{S}_{\mathrm{UM}}$ is found afterwards by applying the linear equation of state (Eqn. 3). Substituting Eqn. 5 and Eqn. 6 into equation Eqn. 13 gives a cubic polynomial function (Eqn. 14) that yields $\mathrm{Q}_{\mathrm{LM}}$. 


$$
\begin{aligned}
& \lambda_{3} \mathrm{Q}_{\mathrm{LM}}^{3}+\lambda_{2} \mathrm{Q}_{\mathrm{LM}}^{2}+\lambda_{1} \mathrm{Q}_{\mathrm{LM}}+\lambda_{0}=0 \text { with } \\
& \lambda_{3}=-\mathrm{H} \\
& \lambda_{2}=2 \mathrm{Q}_{\mathrm{R}}(2 \mathrm{H}-\mathrm{h})+\mathrm{a}_{0} \mathrm{a}_{\mathrm{t}} \mathrm{Q}_{\mathrm{Ut}} \mathrm{H} \\
& \lambda_{1}=0.096 \mathrm{a}_{1}\left(\frac{\mathrm{WHc}}{\mathrm{Q}_{\mathrm{R}} \mathrm{Sc}^{2}}\right)^{1 / 3} \mathrm{H}^{2} \mathrm{WQ}_{\mathrm{R}}-\mathrm{Q}_{\mathrm{R}}(2 \mathrm{H}-\mathrm{h})\left(\mathrm{Q}_{\mathrm{R}}+\mathrm{a}_{0} \mathrm{a}_{\mathrm{t}} \mathrm{Q}_{\mathrm{Ut}}\right)-\mathrm{a}_{0}^{2} \mathrm{a}_{\mathrm{t}}^{2} \frac{\mathrm{Q}_{\mathrm{Ut}}^{2}}{4} \mathrm{H} \\
& \lambda_{0}=-0.048 \mathrm{a}_{1}\left(\frac{\mathrm{WHc}}{\mathrm{Q}_{\mathrm{R}} \mathrm{Sc}^{2}}\right)^{1 / 3} \mathrm{H}^{2} \mathrm{~W}\left(\mathrm{Q}_{\mathrm{R}}+\mathrm{a}_{0} \mathrm{a}_{\mathrm{t}} \mathrm{Q}_{\mathrm{Ut}}\right) \mathrm{Q}_{\mathrm{R}}
\end{aligned}
$$

203 For the EBM, only the negative real root of the $\mathrm{Q}_{\mathrm{LM}}$ makes sense physically (indicating lower-

204 layer flow into the estuary) and Eqn. 14 always has only one valid root with positive $\mathrm{a}_{0}$ and $\mathrm{a}_{1}$ 205 values. Substituting the $\mathrm{Q}_{\mathrm{LM}}$ solution into volume conservation (Eqn. 5) yields the $\mathrm{Q}_{\mathrm{UM}}$ solution 206 in Eqn. 15.

$$
\mathrm{Q}_{\mathrm{UM}}=\mathrm{Q}_{\mathrm{R}}-\mathrm{Q}_{\mathrm{LM}}
$$

207 Subsequently, $\rho_{\mathrm{UM}}$ is gained from water mass conservation (Eqn. 6) as given in Eqn. 16.

$$
\rho_{\mathrm{UM}}=\left(\rho_{\mathrm{R}} \mathrm{Q}_{\mathrm{R}}-\rho_{\mathrm{LM}} \mathrm{Q}_{\mathrm{LM}}+\rho_{\mathrm{LM}} \mathrm{a}_{0} \mathrm{a}_{\mathrm{t}} \frac{\mathrm{Q}_{\mathrm{Ut}}}{2}\right) /\left(\mathrm{Q}_{\mathrm{UM}}+\frac{\mathrm{a}_{0} \mathrm{a}_{\mathrm{t}} \mathrm{Q}_{\mathrm{Ut}}}{2}\right)
$$

$208 \mathrm{~S}_{\mathrm{UM}}$ can be solved using the linear equation of state (Eqn. 3) with $\rho_{\mathrm{UM}}$ calculated in Eqn. 16. 209 Alternately, substituting the linear equation of state (Eqn. 3) for all the densities in Eqn. 16 and 210 applying the volume balance (Eqn. 5) yields an equation for $\mathrm{S}_{\mathrm{UM}}$ that is analogous to Eqn. 16 but 211 with the densities replaced by salinities (Eqn. 17).

$$
\mathrm{S}_{\mathrm{UM}}=\mathrm{S}_{\mathrm{LM}}\left(-\mathrm{Q}_{\mathrm{LM}}+\frac{\mathrm{a}_{0} \mathrm{a}_{\mathrm{t}} \mathrm{Q}_{\mathrm{Ut}}}{2}\right) /\left(\mathrm{Q}_{\mathrm{UM}}+\frac{\mathrm{a}_{0} \mathrm{a}_{\mathrm{t}} \mathrm{Q}_{\mathrm{Ut}}}{2}\right)
$$

212 Note that $S_{U M}$ reduces to $S_{L M}\left|Q_{L M}\right| / Q_{U M}$ if tidal pumping is omitted by setting $a_{0}$ to zero. 


\subsection{Implementation of EBM in Earth system models}

214

215

216

217

218

219

220

221

222

223

224

225

226

227

228

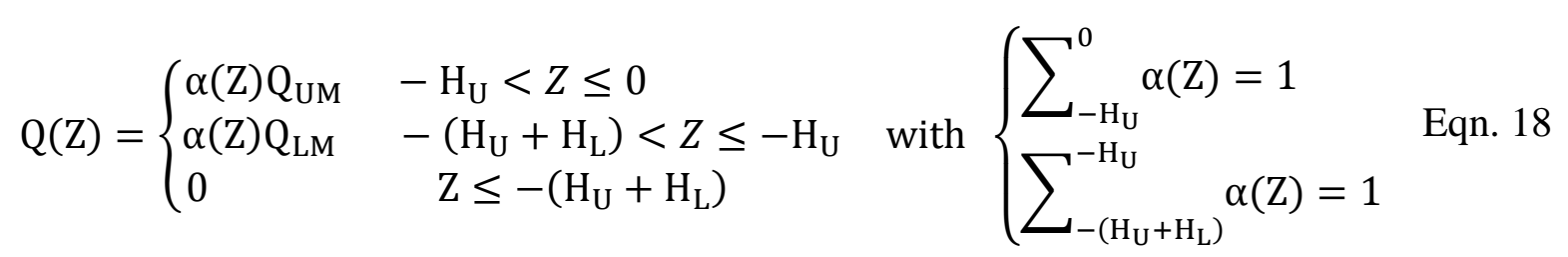

229 The model vertical coordinate $\mathrm{Z}$ in Eqn. 18 is positive upwards from the surface, $\mathrm{Z}$ is negative 230 throughout the water column. The $\alpha(\mathrm{Z})$ is a flexible vertical weighting function, and the 231 summation of the $\alpha(\mathrm{Z})$ within the upper layer has to equal one, and it is the same for the lower 232 layer (e.g. $\alpha_{1}=\alpha_{2}=\alpha_{3}=\alpha_{4}=0.5$ in the Figure 2 a). The volume flux $Q_{U M}$ is positive since it 
233 enters the ocean, and $\mathrm{Q}_{\mathrm{LM}}$ is negative since it leaves the ocean. In practice the volume fluxes are 234 implemented as velocities at the velocity-grid on the land-ocean interface. The approaches will 235 vary between different numerical grid structures. For the staggered C-grid, the velocity points are 236 in the middle of the tracer grid cell lateral faces. Thus, the implemented velocity for each grid 237 cell can be found by dividing the weighted volume flux by the area of the grid cell face on the 238 land-ocean boundary. For the staggered B-grid, the velocity points are at the corners of tracer 239 grid cell. Then the volume fluxes can be evenly split into the two adjacent velocity points. The 240 vertical integral of volume flux will equal the riverine discharge $Q_{R}$ on the ocean-land boundary 241 after correct coupling implementation.

242 The lower layer salinity $S_{\mathrm{LM}}$ for the salt flux calculations is calculated with Eqn. 19.

$$
\mathrm{S}_{\mathrm{LM}}=\frac{\sum_{-\left(\mathrm{H}_{\mathrm{U}}+\mathrm{H}_{\mathrm{L}}\right)}^{-\mathrm{H}_{\mathrm{i}, \mathrm{k}}}\left(\mathrm{S}_{\mathrm{i}}\right)}{\mathrm{H}_{\mathrm{L}}}
$$

243 The $\mathrm{dZ}_{\mathrm{k}}$ in Eqn. 19 is the thickness of the tracer grid cell at vertical level k (e.g. $\mathrm{dZ}_{3}=\mathrm{dZ}_{4}$ and $244 \mathrm{~S}_{\mathrm{LM}}=\mathrm{S}_{\mathrm{i}, 3} / 2+\mathrm{S}_{\mathrm{i}, 4} / 2$ in the Figure $2 \mathrm{a}$ ). $\mathrm{S}_{\mathrm{LM}}$ also is used to force the EBM. Salt fluxes for the 245 upper layer involve the effective salinity $S_{\mathrm{EFF}}$ calculated in Eqn. 20.

$$
S_{\mathrm{EFF}}=\mathrm{S}_{\mathrm{LM}} \frac{\mathrm{Q}_{\mathrm{LM}}}{\mathrm{Q}_{\mathrm{LM}}-\mathrm{Q}_{\mathrm{R}}}
$$

$246 \mathrm{~S}_{\mathrm{EFF}}$ is appropriate for the advective salinity balance $S_{\mathrm{EFF}} \mathrm{Q}_{\mathrm{UM}}=\mathrm{S}_{\mathrm{LM}}\left|\mathrm{Q}_{\mathrm{LM}}\right|$ imposed by this 247 coupling method at the coastal boundary. $S_{\mathrm{EFF}}$ equals $\mathrm{S}_{\mathrm{UM}}$ if tidal pumping is not included in the 248 EBM solution (i.e $a_{0}$ is zero), but is otherwise lower than $S_{U M}$ (Eqn. 17). For all grid cells within 249 the lower layer $\left(\mathrm{H}_{\mathrm{L}}\right)$, the land-ocean interface should have the same tracer value $\mathrm{S}_{\mathrm{LM}}$. And for all 250 grid cells within the upper layer $\left(\mathrm{H}_{\mathrm{U}}\right)$, the land-ocean interface should have the same tracer value 
$251 \mathrm{~S}_{\mathrm{EFF}}$. In practice, the salinity value on the ghost grid cells might need to be calculated with the

252 employed tracer advection scheme, so that the salinity values at the land-ocean boundary can be

253 ensured. The salt fluxes are calculated by multiplying the salinity by volume fluxes crossing the

254 coastal boundary. The vertical integral of the total salt flux on the coastal boundary will be zero

255 after correct coupling implementation.

\section{$256 \quad$ 3.7.2 Implementation as virtual salt fluxes}

257 In this study, the EBM is implemented within CESM to test the global performance. The Parallel

258 Ocean Program version 2 (POP2) is the ocean component of CESM (Danabasoglu, et al., 2012).

259 The riverine freshwater runoff in the POP2 is treated as a virtual salt flux (VSF) through the air-

260 sea interface, so there are no volume or mass fluxes crossing the land-ocean coastal boundary. In

261 this situation, the riverine runoff and estuarine exchange are handled as vertical salt flux

262 convergence terms in the salinity conservation equation (Eqn. 21) (Tseng, et al., 2016):

$$
\begin{gathered}
\frac{\mathrm{DS}}{\mathrm{Dt}}=\nabla(\mathrm{K} \nabla \mathrm{S})+\frac{\partial}{\partial \mathrm{Z}}\left[\kappa\left(\frac{\partial \mathrm{S}}{\partial \mathrm{Z}}-\gamma_{\mathrm{S}}\right)\right]-\frac{\partial \mathrm{F}^{\mathrm{R}}}{\partial \mathrm{Z}}-\frac{\partial \mathrm{F}^{\mathrm{REX}}}{\partial \mathrm{Z}} \\
\text { with }\left.\kappa \frac{\partial \mathrm{S}}{\partial \mathrm{Z}}\right|_{\mathrm{Z}=0}=-\mathrm{F}_{\mathrm{S}}(0) \text { and } \kappa \gamma_{\mathrm{S}} \mathrm{I}_{\mathrm{Z}=0}=0
\end{gathered}
$$

263 where $\mathrm{Z}$ is the POP2 vertical coordinate (positive upwards from the surface, Figure $2 \mathrm{~b}$ ), $\mathrm{K}$ is the 264 isopycnal skew-diffusion tensor, $\kappa$ is the diapycnal diffusivity and $\kappa \gamma_{S}$ is the KPP counter 265 gradient flux in the boundary layer. The $\mathrm{F}_{\mathrm{S}}(0)$ includes all the freshwater VSF applied as surface 266 boundary condition and is positive upwards (when salt is removed from the ocean), but this term 267 excludes river runoff for the EBM implementations. The details of $F_{S}(0)$ treatment is discussed 268 in Tseng, et al. (2016). The last two terms on the right-hand side of Eqn. 21 represent the salt 269 flux convergences given by $-\partial \mathrm{F}^{*} / \partial \mathrm{Z}$. The riverine freshwater VSF F ${ }^{\mathrm{R}}$ (Eqn. 22) and estuarine 
exchange flow VSF F ${ }^{\mathrm{REX}}$ (Eqn. 23) are distributed vertically in the water column by specifying

271 layer thicknesses $\mathrm{H}_{\mathrm{U}}$ and $\mathrm{H}_{\mathrm{L}}$.

$$
\begin{aligned}
& \mathrm{F}^{\mathrm{R}}(\mathrm{Z})=\left\{\begin{array}{l}
\mathrm{F}^{\mathrm{R}}(0)\left(1+\frac{\mathrm{Z}}{\mathrm{H}_{\mathrm{U}}}\right) \\
0 \\
0 \\
\mathrm{Z} \leq-\mathrm{H}_{\mathrm{U}}<Z \leq 0
\end{array} \text { with } \mathrm{F}^{\mathrm{R}}(0)=\mathrm{Q}_{\mathrm{R}} \mathrm{S} \quad \text { Eqn. } 22\right.
\end{aligned}
$$

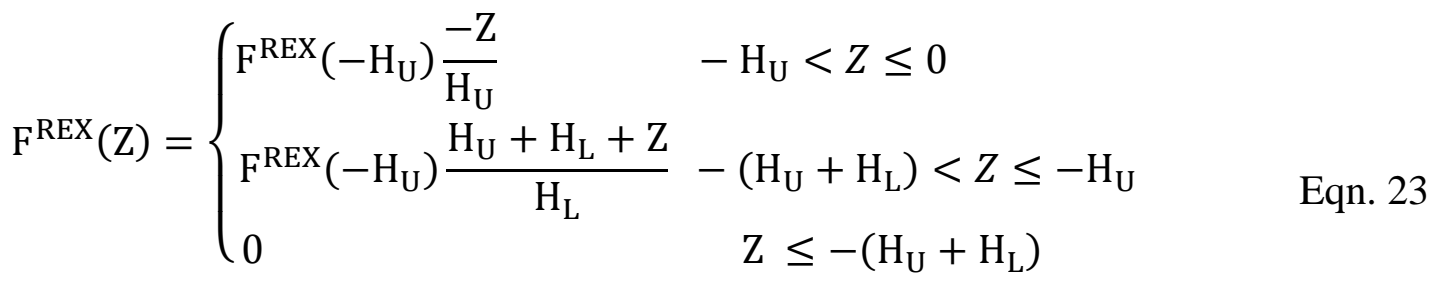

$$
\begin{aligned}
& \text { with } \mathrm{F}^{\mathrm{REX}}\left(-\mathrm{H}_{\mathrm{U}}\right)=-\mathrm{Q}_{\mathrm{LM}}\left(\mathrm{S}_{\mathrm{LM}}-\mathrm{S}_{\mathrm{EFF}}\right)
\end{aligned}
$$

272 The choice of $\mathrm{H}_{\mathrm{U}}$ and $\mathrm{H}_{\mathrm{L}}$ in POP2 are flexible and do not have to match the EBM layer

273 thicknesses $(\mathrm{H}-\mathrm{h}$ and $\mathrm{h})$. The upper and lower layers in the POP2 each have to span at least one

274 vertical level of the tracer grid cell. The treatment for the riverine freshwater (Eqn. 22) is same as

275 the approach of Tseng, et al. (2016). The riverine freshwater VSF $F^{\mathrm{R}}$ is positive and increases

276 toward the ocean surface (Eqn. 22), thus $\mathrm{F}^{\mathrm{R}}$ is divergent $\left(-\partial \mathrm{F}^{\mathrm{R}} / \partial \mathrm{Z}<0\right)$ and makes negative

277 contributions in the salinity conservation equation (Eqn. 21) within the upper layer $\left(\mathrm{H}_{\mathrm{U}}\right)$. The

278 vertical integral of $-\partial \mathrm{F}^{\mathrm{R}} / \partial \mathrm{Z}$ over the entire water column yields $-\mathrm{F}^{\mathrm{R}}(0)$. In nature, lower-layer

279 water is upwelled within the estuary and then transported back into the coastal ocean with the 280 upper-layer outflow. The lower-layer (saltier) water entering the estuary is entrained from the 281 continental shelf and there is horizontal divergence in the vicinity of the entrainment zone that 282 requires a downwelling of near-surface (fresher) water if a steady-state volume balance is 283 maintained. The net effects on the salinity field are bringing saltier water to the surface within 284 the estuary and moving fresher water to deeper depths somewhere outside the estuary. In this 285 coupling method both the upwelling and downwelling are applied within the same ocean tracer 
286 grid cells as the river runoff, thus there is no net volume flux due to exchange flow within the

287 water column and only the vertical distribution of net salt fluxes needs to be represented. In

288 POP2, the exchange flow is applied as upwelling VSF $\left(\mathrm{F}^{\mathrm{REX}}\right)$ that increases from zero at bottom

289 of lower layer $\left(-\mathrm{H}_{\mathrm{U}}-\mathrm{H}_{\mathrm{L}}\right)$ toward the layer interface $\left(-\mathrm{H}_{\mathrm{U}}\right)$, then decreases to the zero at ocean

290 surface (Eqn. 23). Note that the $Q_{\mathrm{LM}}$ is negative because the water is taken away from the ocean

291 (Figure 1), so the $\mathrm{F}^{\mathrm{REX}}$ is positive (upward) (Figure $2 \mathrm{~b}$ ). $\mathrm{F}^{\mathrm{REX}}$ is convergent $\left(-\partial \mathrm{F}^{\mathrm{REX}} / \partial \mathrm{Z}>0\right.$,

292 positive contributions in Eqn. 21) within the upper layer $\left(\mathrm{Z}>-H_{\mathrm{U}}\right)$ and divergent

$293\left(-\partial \mathrm{F}^{\mathrm{REX}} / \partial \mathrm{Z}<0\right.$, negative contributions in Eqn. 21) within the lower layer (Figure $2 \mathrm{~b}$ ). The

294 tracer values for calculating $\mathrm{F}^{\mathrm{REX}}$ are the lower layer salinity $\mathrm{S}_{\mathrm{LM}}$ (Eqn. 19), and the effective

295 estuarine outflow salinity $\mathrm{S}_{\mathrm{EFF}}$ (Eqn. 20). With this coupling method, the exchange volume flux

296 balances within the same column of ocean grid cells, so the vertical integral of $-\partial \mathrm{F}^{\mathrm{REX}} / \partial \mathrm{Z}$ over

297 the water column is zero.

\section{4. Columbia River test case}

\subsection{Observational data}

301 The EBM is tested and evaluated for the Columbia River estuary with observations and output 302 from a high-resolution Regional Ocean Modeling System (ROMS) simulation. For comparisons 303 with observations, the EBM is forced with the daily discharge for 2013 calculated as the sum of 304 USGS stream-gage observations on the Columbia River (\#14105700) and its downstream 305 tributaries in Willamette River (\#14197900), Lewis River (\#14222500 and \#14220500) and 306 Cowlitz River (\#14243000). Tidal information used to assess tidal pumping is derived from the 307 NOAA sea level record at Hammond, OR (\#9439011) near the Columbia River mouth. The daily 
tidal amplitude $\left(\eta_{t}\right)$ is set by averaging the two high tides each day if the EBM forcing includes the spring-neap tidal variations. Otherwise, the record-averaged tidal amplitude is used. The

310 corresponding tidal velocity amplitude $\left(\mathrm{u}_{\mathrm{t}}\right)$ forcing is estimated from the depth-averaged long-

311 wave solution $u_{t}=\eta_{t} \sqrt{g / H}$. The EBM upper-layer salinities are compared to daily-averaged 312 estuarine outflow salinities calculated from observations collected at the NOAA National Data 313 Buoy Center Station JTAW1 (collected 6.4 meters below mean water level at a 6-minute 314 interval). Any data gaps are linearly interpolated prior to daily averaging. The oceanic inflow 315 water salinity is set to 32 PSU since no observational record is available for the time period. This 316 value is a reasonable estimate for ambient shelf waters, but it excludes time variations of shelf317 water salinity. The total depth of estuary box is calculated from the General Bathymetric Chart of 318 the Oceans (GEBCO) global 30 arc-second data, which gives the root mean squared depth of 31910.93 meters. The EBM upper layer has the same thickness as the lower layer (the interface is at 320 mid-depth). The box width is set to $3.67 \mathrm{~km}$, the mouth width measured from Google Earth.

\section{4.2. Comparisons with observations}

322 In this testing, the diffusion adjusting constants $\mathrm{a}_{0}$ and $\mathrm{a}_{1}$ are constrained using the MATLAB 323 function "fminsearch" (Lagarias, et al., 1998), that gives optimized parameters for the smallest 324 Root Mean Squared Error (RMSE) of outflow salinities between EBM and observations. The 325 best-fit values are $\mathrm{a}_{0}=1.20$ and $\mathrm{a}_{1}=0.93$ (Table 1 ). The observed Columbia River estuary outflow 326 salinities show clear spring-neap tidal variations (Figure 3 a), with amplitudes of approximately 3275 to 8 PSU. Outflow salinities are fresher between April and July and saltier from August to 328 December due to the river discharge annual cycle. The EBM solution performs well in 329 representing both the spring-neap outflow salinity variations and the seasonal salinity changes 
(Figure 3). The RMSE between EBM results and observations is 1.7 PSU (10\% of the observed mean outflow salinity) with the squared correlation coefficient $\left(\mathrm{r}^{2}\right)$ of 0.70 and bias of -0.06 PSU.

For ESMs focused on long-term variations of the global ocean, the spring-neap tidal variations may become less important. So the EBM without spring-neap tidal variations is tested with constant tidal amplitude $\left(\eta_{t}=1.01 \mathrm{~m}, \mathrm{u}_{\mathrm{t}}=0.96 \mathrm{~m} \mathrm{~s}^{-1}\right)$. A 5th order Butterworth low-pass filter with cut-off period of 33 days is employed to filter out the spring-neap signals (and higher frequency variations) from the observed river discharge for forcing and the observed outflow salinity data for comparison. The $\mathrm{a}_{1}$ value (0.93) is kept the same as before. In this case, the tidal pumping geometric ratio $\mathrm{a}_{\mathrm{t}}$ is constant, so it is combined with $\mathrm{a}_{0}$ to yield the tidal pumping adjusting constant $a_{2}=a_{0} a_{t}$. This simplifies the EBM parameter space in the ESMs. The optimization function gives $\mathrm{a}_{2}=0.70$. The EBM calculated outflow salinities compared to the filtered observations have RMSE of 1.11 PSU, $\mathrm{r}^{2}$ of 0.81 and mean bias of -0.02 PSU (Figure 3 b). The EBM follows the seasonal variation of Columbia River outflow salinities, although it has a saltier outflow in spring and fresher outflow in summer. The EBM works well to represent the estuary outflow salinity in the case of Columbia River, which encourages its application to other estuaries and within ESMs.

\subsection{ROMS simulation data}

Observational time series of volume fluxes at estuary mouths are uncommon, but regional ocean models can provide these fluxes. A pre-existing ROMS simulation of the Columbia River and the adjacent ocean region provides a comparison for EBM results. The model details are described in Giddings, et al. (2014). The comparison data are the ROMS results for 2005. They are tidally averaged with a low-pass Godin 24/24/25 filter (Godin, 1972). Volume fluxes are 
352 calculated at the head $\left(Q_{R}\right.$ forcing for the EBM) and at the estuary mouth $\left(Q_{U M}\right.$ and $Q_{L M}$ for

353 comparison with EBM). $\mathrm{Q}_{\mathrm{LM}}$ for ROMS is determined by the spatially integrating all landward

354 velocities through the mouth. $\mathrm{Q}_{\mathrm{UM}}$ for ROMS is calculated according to Eqn. 5 for the most 355 consistent comparison with EBM steady dynamics. The calculated $\mathrm{Q}_{\mathrm{UM}}$ is somewhat lower than 356 the spatial integral of seaward velocities through the mouth because it omits the seaward 357 compensation flow for the landward Stokes transport (Ianniello, 1979 and 1981) that is not 358 included in EBM dynamics. The ROMS inflow salinities through the mouth $\left(\mathrm{S}_{\mathrm{LM}}\right.$ forcing for 359 EBM) are calculated by dividing total landward salinity fluxes through the mouth by $\mathrm{Q}_{\mathrm{LM}}$. The ROMS outflow salinities $\left(\mathrm{S}_{\mathrm{UM}}\right.$ for comparison with $\left.\mathrm{EBM}\right)$ are calculated in analogous fashion to $361 \mathrm{~S}_{\mathrm{LM}}$ and can be compared to EBM output. EBM tidal forcing for 2005 is calculated from 362 observed harmonic constituents as in the previous comparison. The same estuary box dimensions 363 are employed as for the comparison with observations, and the mixing constants $\mathrm{a}_{0}$ and $\mathrm{a}_{1}$ also 364 are kept same as the previous observation comparison run, so that the EBM parameter values can 365 be evaluated with ROMS results.

\subsection{Comparison to the ROMS simulation}

367 The comparisons of EBM with ROMS are shown in Figure 4. For the estuarine outflow salinity 368 (Figure 4 a), EBM has a RMSE of 3.11, $\mathrm{r}^{2}$ of 0.54 and bias of -1.33 PSU. The agreement can be 369 increased by changing the mixing coefficients to find the best-fit EBM solution for ROMS, but 370 this was not done as the coefficients already are set based on observations. The EBM includes

371 the spring-neap cycles of the outflow salinity, although their amplitudes are smaller than in 372 ROMS. In general, the lower-layer inflow salinity has much smaller variations than the upper373 layer outflow salinity which has considerable variability associated with tides and river discharge. 374 A couple of shelf freshening events in March and May cause drops of EBM outflow salinity that 
375 are not shown in the ROMS simulation. The mismatch is attributed to the EBM steady state salt 376 balance that does not allow for a delayed and smoothed response to sudden forcing changes seen 377 in nature (MacCready, 1999) (MacCready, 2007) and the ROMS results. This is not a major 378 limitation in ESMs since periods of interest are usually seasonal to multi-decadal variability and 379 estuary response generally occurs over shorter time scales.

380 The outflow volume fluxes from EBM matches well with ROMS results (Figure $4 \mathrm{~b}$ ), with 381 RMSE of $513 \mathrm{~m}^{3} \mathrm{~s}^{-1}\left(7.6 \%\right.$ of the ROMS mean outflow volume flux), $\mathrm{r}^{2}$ of 0.89 and a $382125 \mathrm{~m}^{3} \mathrm{~s}^{-1}$ bias. The lower-layer inflow volume fluxes from the EBM and ROMS have similar 383 mean values, but the EBM result has less high-frequency variability. In the high discharge period, 384 the EBM tends to overestimate the outflow volume flux. Physically, with rising river discharge, 385 the stratification in an estuary increases, which can inhibit turbulent mixing through the layer 386 interface and reduce estuary exchange flow. In the case of Columbia River estuary, it changes 387 from a partially mixed type to the salt wedge type with increased vertical stratification. EBM can 388 capture the estuarine type transition by reducing the lower-layer volume flux (associated with 389 estuary exchange flow), but it has a weaker response than in ROMS. Nevertheless, EBM works 390 well to represent the seasonal, even spring-neap, variations of Columbia River estuary outflow 391 volume flux from ROMS results.

392 To test the EBM without the spring-neap tidal signal, all ROMS data are smoothed with the same 393 low-pass filter used for the no-spring-neap observational data. The filtered river discharge and 394 lower-layer salinity are used to force the EBM, and the filtered outflow volume fluxes and 395 salinities are compared to EBM results. The EBM employs the same dynamic parameters as in 396 the comparison with the filtered observations (Table 1). The agreement is improved with RMSE 397 of 1.74 PSU, $\mathrm{r}^{2}$ of 0.82 and a -1.20 PSU bias for outflow salinity, and RMSE of $330 \mathrm{~m}^{3} / \mathrm{s}, \mathrm{r}^{2}$ of 
3980.98 and a $123 \mathrm{~m}^{3} \mathrm{~s}^{-1}$ bias for outflow volume fluxes (Figure $4 \mathrm{c}$ and $\mathrm{d}$ ). It indicates that the 399 EBM works well for long-period or low-frequency forcing. As the high frequency forcing is 400 filtered out, estuaries tend to achieve a quasi-steady-state balance that is well represented by 401 EBM steady-state dynamics. Thus, the EBM can work well in the ESMs even though it neglects 402 the short-term estuary adjustment.

\section{Applying the EBM globally}

405 One challenge to implementing the EBM in an ESM is specifying parameters for all estuaries 406 globally. The Dai and Trenberth (2002) dataset shows that the 20 largest rivers (the global top 20) 407 contribute to over $60 \%$ of total global riverine freshwater runoff into the oceans. The Amazon 408 River alone accounts for almost $25 \%$ of total global discharge. Many of the largest rivers have 409 been well studied, therefore observational data and/or regional simulations exist to calibrate 410 EBM mixing parameters and set box geometry. The Columbia River is a good example that has 411 both observational and simulation data. Smaller rivers in the dataset have smaller individual 412 contributions on freshwater discharge, but their summation is significant globally and their 413 individual inputs are important locally. Many of these rivers do not have enough data to calibrate 414 EBM parameters. A short path to get the EBM working for these rivers is to find a universal 415 relationship between riverine forcing and estuarine response.

416 Hansen and Rattray (1966) developed the stratification-circulation diagram to quantitatively 417 classify estuaries. They found that scaled stratification $\delta S / S_{0}$ (the top-to-bottom salinity 418 difference divided by the sectional mean) in the estuary depends on the densimetric Froude 419 number $Q_{R} /(\mathrm{cWH})$. In general, the stratification increases with rising Froude number. The EBM 420 can be parameterized for the rivers outside of global top 20 in an ESM, so that their outflow 
421 salinities (and mouth stratification) follow this general trend. The original scaled stratification is

422 modified to $\left(\mathrm{S}_{\mathrm{LM}}-\mathrm{S}_{\mathrm{UM}}\right) / \mathrm{S}_{\mathrm{LM}}$ for application at the EBM mouth. Geyer (2010) applied

423 observations from 13 estuaries (Figure 5), and shows that the bulk stratification rises with

424 increasing densimetric Froude number. Geyer (2010) includes two scalings to predict

425 stratification, but they overestimate stratification for estuaries with high densimetric Froude

426 numbers and do not asymptote to the completely stratified limit.

427 The EBM is set up with a uniform box frame with $\mathrm{H}=10 \mathrm{~m}$ and $\mathrm{h}=5 \mathrm{~m}$. The mixing parameters

428 of the EBM are then optimized to get the smallest RMSE for all with observation points on

429 Figure 5. The width scales out of the solution when expressed in terms of the densimetric Froude

430 number; consequently, the width does not need to be specified. One EBM run includes tidal

431 pumping with $\mathrm{u}_{\mathrm{t}}=1 \mathrm{~m} / \mathrm{s}$ and the other neglects tidal pumping by setting $\mathrm{a}_{2}$ to zero. The EBM

432 solutions follow the general trend of the observations. EBM solutions with or without tidal

433 pumping both converge and asymptote to complete stratification at high flow conditions with

434 larger riverine densimetric Froude numbers. In the lower Froude number region, the EBM with

435 tidal pumping has less stratification, because the tidal pumping helps to increase the estuarine

436 outflow salinity. These results encourage the global application of the EBM and indicate that

437 even the solution without tidal pumping works well. They provide a basis for generic EBM

438 parameters that can be applied even if there is not enough information to set estuary-specific 439 values. 


\section{EBM test in global climate model}

\section{6.1. CESM and EBM settings}

443 The EBM is implemented and tested in the ocean component POP2 of the CESM version 1.1.1

444 with nominal $1^{\circ}$ horizontal resolution. POP2 has 60 vertical z-levels with $10 \mathrm{~m}$ resolution in the

445 first 15 levels and is stretched to $250 \mathrm{~m}$ resolution for the deepest ocean. For the runs discussed

446 here, the ocean and sea-ice components are active, while the atmospheric component and river

447 freshwater input are decoupled and prescribed with the 1948-2007 COREII forcing (Large and

448 Yeager, 2009; Griffies et al, 2009). The model is run for 60 years (one cycle of the forcing), and

449 the climatological averages of the last 30 years' results are used for evaluations.

450 The EBM parameters are specified individually for each of the global top 20 rivers (Table 2).

451 The total depth $(\mathrm{H})$ is either picked from literature or calculated from the General Bathymetric

452 Chart of the Oceans (GEBCO) data set (IOC, et al., 2003) as the root mean square depth in the

453 selected estuary area. The width (W) of the box at its mouth is either from literature or measured

454 from the Google Earth Pro v.7.1.2.2041 with its Line Ruler tool. If there is more than one

455 channel connecting to the ocean, the box width is taken as the combined width of the channels.

456 The lower-layer thickness is taken as half the total depth for all rivers. The mixing parameters

$457\left(a_{1}\right.$ and $\left.a_{2}\right)$ of the EBM for top 20 rivers are individually optimized to match the observed

458 outflow salinity with MATLAB function "fminsearch" (Lagarias, et al., 1998) in offline

459 integrations. The 60-year-averaged monthly discharge of each individual river is taken from the

460 Dai and Trenberth (2002) database. The annual mean of Mean High Water (MHW) level is

461 regenerated from the Regional and Local Tidal Solutions of the OSU Tidal Data Inversion

462 (Egbert \& Erofeeva, 2002), literature studies, or NOAA buoys. Finally, the optimized mixing

463 parameters are found by minimizing the RMSE between the calculated annual mean outflow 
464 salinity and comparison data from published observations or regional numerical studies. The 465 studies used to determine the mixing parameters are listed in Table 2. For other rivers, outside of 466 the top 20, the default EBM has a common depth of $10 \mathrm{~m}$ and the mouth width of $2 \mathrm{~km}$. The 467 mixing parameters are from the generic fit described in the previous section (Figure 5). The 468 contribution of tidal pumping in the default EBM is neglected.

469 Three test cases (VSFEBM, VSFROF, and VSFSPRD, where "VSF" indicates the virtual salt 470 flux coupling method) are used to illustrate the effects of estuary exchange in POP2. The EBM is 471 implemented in the VSFEBM case for all rivers in POP2. The VSFROF is a comparison case in 472 which the EBM exchange circulation is not implemented and the same runoff ("ROF") is applied, 473 so only riverine freshwater convergence term $\left(-\partial \mathrm{F}^{\mathrm{R}} / \partial \mathrm{Z}\right)$ is included (Eqn. 21). The layer 474 thicknesses for coupling with CESM are $\mathrm{H}_{\mathrm{U}}=20 \mathrm{~m}$ (spanning the top two grid levels) and $475 \mathrm{H}_{\mathrm{L}}=20 \mathrm{~m}$ (spanning the next two grid levels) (Figure $2 \mathrm{~b}$ ). If the local water depth is less than $47640 \mathrm{~m}, \mathrm{H}_{\mathrm{U}}$ is held constant and $\mathrm{H}_{\mathrm{L}}$ is reduced. Each river runoff point and the corresponding 477 exchange flow (in VSFEBM only) is mapped to a single T-grid column near the river mouth in 478 the VSFEBM and VSFROF cases. The VSFSPRD case represents the runoff treatment used in 479 prior studies (e.g. Tseng, et al., 2016 experiment B300CS): the riverine freshwater is included in 480 the $F_{S}(0)$ term as surface boundary condition in Eqn. 21 and horizontally spread over a large 481 region (by a e-folding length scale of $1000 \mathrm{~km}$ with a maximum spreading radius of $300 \mathrm{~km}$ 482 Gaussian distribution) rather than distributed vertically and focused horizontally at the runoff 483 points as in the other cases. The other differences for VSFSPRD are the constant global reference 484 salinity for riverine freshwater VSF computation (instead of a time and spatially variable 485 reference salinity) and no EBM. 


\subsection{Interpretation of CESM results}

487 The sea surface salinity (SSS) of the VSFEBM case and differences from other cases are shown

488 in Figure 6. Fresh regions are evident near all major river mouths. There are large differences

489 between the VSFEBM and VSFSPRD cases that exceed 1 PSU in many areas near major rivers 490 (the SSS difference even exceeds 7 PSU near the Amazon River mouth) (Figure 7). VSFEBM 491 and VSFROF are fresher than VSFSPRD adjacent to river mouths because runoff from each 492 river is focused at one point. Introducing river inputs over large spreading regions in VSFSPRD 493 is one reason VSFEBM and VSFROF are saltier at most other points offshore of major rivers. 494 Also the offshore SSS is higher in VSFEBM and VSFROF because of the direct effects of 495 vertically distributing the river inputs over a thicker layer (instead of immediately at the surface), 496 and riverine freshwater VSF differences due to the local (instead of global) reference salinity. 497 SSS at river mouths are further increased in VSFEBM due to the upwelling of saltier waters via 498 estuary exchange flow VSF convergence (Eqn. 21). Indirect effects arise from coastal 499 stratification and circulation changes as well as advection by ocean currents that transports 500 salinity differences to remote areas (especially in the North Atlantic and Arctic) (Tseng, et al., 501 2016).

502 Comparison between VSFEBM and VSFROF isolates the effects of introducing estuary 503 exchange. VSFEBM is saltier at river runoff points because of the vertical salt flux imposed by 504 EBM. VSFEBM is also (approximately 0.1 PSU) saltier in many coastal regions. There are, 505 however, several regions where SSS is lower in VSFEBM; remote freshening $(<0.05$ PSU) 506 spreads into the North Atlantic that is linked to the St. Lawrence and the Amazon. The 507 freshening relative to VSFROF is counterintuitive and is linked to secondary effects resulting 508 from modifications to stratification, ocean currents, and the local reference salinities (that evolve 
509 differently in the two cases) used in the riverine freshwater VSF calculation. Similar freshening 510 occurs for the Changjiang, Bay of Bengal, and Kara Sea (Figure 6). Overall, the CESM case 511 comparison indicates significant local, regional, and even global sensitivity to including 512 estuarine dynamics.

513 The Columbia and Amazon Rivers provide examples of model sensitivity to the treatment of 514 river inputs. The SSS is freshest close to the coast near both rivers (Figure 7). As mentioned, 515 VSFEBM is fresher than VSFSPRD and saltier than VSFROF at the focused runoff points. For 516 the Columbia, these same differences extend along the coast. Farther away from the coast, 517 VSFEBM is saltier than VSFSPRD for both river regions due to the horizontal spreading of 518 runoff in VSFSPRD and other factors mentioned above. The differences between VSFEBM and 519 VSFROF in the Columbia show the anticipated higher SSS originating from the exchange flow 520 VSF convergence imposed by estuary circulation. Near the Amazon, VSFEBM has lower 521 salinities than VSFROF due to the secondary effects described above; the influence of the 522 Amazon contributes to differences throughout the North Atlantic. Salinity stratification near the 523 river mouth changes among cases (Figure 8). VSFEBM is less stratified than VSFROF and 524 removes the problematic near-bottom salinity overshoot (>45 PSU) near the Amazon and other 525 large rivers that otherwise occurs for focused river inputs. The salinity overshooting is also found 526 by Tseng, et al. (2016) in the sensitivity tests of the riverine freshwater input approaches. In this 527 previous study, the salinity over- and under-shooting occur at river mouths with large runoff and 528 intensify as the horizontal spreading area for riverine freshwater inputs is decreased. The estuary 529 exchange flow imposed by the EBM avoids large salinity numerical artifacts without having to 530 impose arbitrarily large horizontal spreading regions as in VSFSPRD. 
531 The modeled salinity profiles are further compared with salinity climatology from high 532 resolution (0.25-degree) World Ocean Atlas 2013 (WOA) (Zweng, et al., 2013); the nearest533 neighbor point to the corresponding POP grid cell are used. The spatial filtering in WOA (Zweng, 534 et al., 2013) tends to create a positive salinity bias in the coastal ocean, especially in the regions 535 close to the riverine freshwater sources, because typically higher offshore salinities contribute to 536 the filtered coastal salinity values. The native World Ocean Database 2013 (WOD) salinities also 537 are averaged within each POP T-grid cell to avoid the influence of spatial filtering. The model 538 vertical salinity profiles at Columbia River mouth are plotted against corresponding WOA and 539 WOD profiles (Figure 8 a). None of model results agree with climatologies through the entire 540 water column, but VSFSPRD surface salinities are closer to the spatially filtered WOA and the 541 other cases are closer to WOD. There are no WOD data available for the Amazon River mouth 542 T-grid cell and the WOA has a surface salinity (at $\mathrm{z}=0$ ) without any subsurface data; therefore no 543 profile comparison can be made.

544 The sensitivity analysis in this paper has focused on long-term mean salinity fields, but seasonal 545 cycles also are important. The seasonal SSS cycle (represented as monthly averages over the 30546 year analysis period) at Columbia, Amazon, Brahmaputra and St. Lawrence river mouths are 547 plotted for the three CESM testing runs (Figure 9). For all four rivers, there are clear seasonal 548 cycles that vary among the runs. The VSFSPRD case has higher salinities because the river 549 inputs are spread over large areas (as previously described) and a seasonal cycle that can be 550 larger (e.g. Amazon), smaller (e.g. Columbia and Brahmaputra), or similar (e.g. St. Lawrence) to 551 the other cases. It is counterintuitive that the Amazon cycle is largest in the VSFSPRD case, but 552 the contributing factors include no vertical spreading of the strong river runoff, changes related 553 to the reference salinity for VSF calculation, and interactions with the ambient ocean currents. In 
554 all four rivers, the VSFEBM case has higher SSS than the VSFROF case due to the vertical salt 555 flux imposed by estuarine exchange flows (as previously described), but the seasonal cycles are 556 quite similar. The Brahmaputra River is discharged into the Bay of Bengal where the SSS varies 557 strongly with monsoon seasonal wind. High-resolution ROMS results in Jana, et al. (2015) show 558 that SSS varies from lower than 24 PSU during the Indian summer monsoon season to 31 PSU 559 during the winter monsoon period on northern Bay of Bengal. The VSFEBM SSS vary between 560 23 PSU and 30.2 PSU and are closest to the ROMS results for the area. The regional model of 561 Rahaman, et al. (2014) suggests the SSS varies in North Bay of Bengal between 29 to 32 PSU, 562 while the VSFEBM results shows smaller and saltier auunal SSS change between 32 and 33 PSU.

563 The modeled annual SSS cycles at the four river mouths discussed above are also compared with 564 WOA and WOD climatologies in the single T-grid cell (Figure 9). For the Columbia, the SSS 565 cycle for VSFSPRD is closer to WOA then other two cases, but all cases have much smaller SSS 566 cycle amplitude than WOD (with a different timing). There are no WOD data available within 567 the T-cell adjacent to the Amazon mouth, and the nearest WOA grid does not have subsurface 568 salinity to make fair comparisons with POP SSS at 5m. At the Brahmaputra River mouth, 569 VSFSPRD is closest to WOA though the WOA amplitude is somewhat larger. The other runs are 570 closer to the large salinity range indicated by WOD with its spiky oscillation of SSS during 571 February to May and low salinity in October. At St. Lawrence River lower estuarine mouth, all 572 runs are considerably fresher than the WOA and WOD salinities (VSFSPRD has the smallest 573 different and VSFROF has the largest difference). It is worth noting that some of the SSS 574 mismatch can be attributed to a mismatch between model runoff location and the natural riverine 575 freshwater distribution (e.g. Saucier et al., 2003). Overall, the comparisons among model results 576 and climatology are not conclusive. There is a tendency for VSFSPRD and WOA to be closer to 
577 each other, but this is likely because the spreading of river inputs in the model and the spatial

578 filtering radius in WOA both smooth the sharpness of the riverine freshwater fronts near the river

579 mouths and increase coastal salinities. VSFROF and VSFEBM have the capacity to include the

580 lower salinities and larger annual cycles indicated by WOD, but it is hard to distinguish which

581 run is better by these comparisons alone. It is also worth noting that differences between the

582 WOA and WOD are at least as large as the differences among model runs. This suggests a need

583 for an improved global climatology that pays particular attention to coastal salinities. Though the

584 model-climatology comparisons are inconclusive, the VSFEBM configuration includes estuarine

585 processes and therefore more of the physics governing river inputs to the ocean.

587 7. Discussion

588 Adding the estuarine exchange flows in POP2 also has impacts on the climate process beyond 589 the costal oceans. It is shown that SSS decreases in North Atlantic and increases in the Pacific, 590 Indian, South Atlantic, and Southern Oceans, although the change is smaller than in coastal 591 regions (Figure $6 \mathrm{c}$ ). Ongoing testing (not shown here) suggests that including the EBM in the 592 fully-coupled CESM may reduce ice formation in the Labrador Sea and can alter the Indian 593 Ocean Dipole. In the current study, the EBM is only applied to salinity, but it will be useful to 594 extend the approach to temperature and biogeochemical tracers in the future. Including nutrient 595 upwelling by estuary exchange flow, for instance, likely will have significant impacts on primary 596 productivity in global climate models in some coastal regions and perhaps farther offshore. It 597 would be best to also include parameterizations that represent the nonconservative 598 biogeochemical transformations within estuaries. 
The EBM is designed for the specific needs of the coarse horizontal resolution climate ocean 600 models with computational constraints. The EBM is physically-based and represents many of the 601 essential estuarine processes. As mentioned in the introduction, Herzfeld (2015) developed a 602 method that continuously adjusts to the landward propagation of an oceanic salt wedge into the 603 estuary and then enforces zero net salt flux through the mouth and a net volume flux equaling 604 river discharge. This solution does increase the salinity of the upper-layer flow from the estuary 605 to the ocean, however it typically will have weaker exchange, be more stratified, and have a 606 fresher upper-layer than the EBM solution since it does not include estuarine tidal mixing, a 607 critically important factor in driving estuary exchange. It is worth mentioning that MacCready 608 (2011) discusses an alternative approach to calculate estuarine exchange flow by using isohaline 609 coordinates that could be incorporated into ocean models. It is important to note that high610 resolution hydrodynamic models of estuaries are able to better represent individual estuaries by 611 including more complex geometries, flow-topography interactions (e.g. sills), wind-forced 612 circulation, and other non-steady dynamics. Consequently, coupling hydrodynamic estuarine 613 models within ESMs will provide a more complete representation of estuarine influences on the 614 global ocean. The computational burden, however, would be far larger than the negligble 615 calculation times for the EBM. In future studies, it will be worthwhile to compare results for the 616 different strategies of representing estuarine processes in ESMs.

\section{Summary}

619 The Estuary Box Model (EBM) is a physically-based approach to represent unresolved estuarine 620 processes in global ocean models such as POP2 within the CESM. Steady-state balances for 621 water volume, density (and salinity via the linear equation of state), and gravitational potential 
622 energy are employed. It is assumed that the estuary length (associated with the saltwater 623 intrusion) is fully-adjusted to the river discharge and tidal mixing. Analytical solutions for

624 estuarine outflow salinity and volume fluxes are found by considering river forcing and vertical

625 and horizontal tidal mixing that drive estuarine exchange and transform pure river water to an 626 outgoing mixture of freshwater and saltwater. The forcings required for the EBM are river 627 discharge, inflowing seawater salinity, and tidal amplitude (if horizontal diffusion via tidal 628 pumping is included). Five parameters are required for each estuary: width, total depth, lower 629 layer thickness, and two adjustable dimensionless vertical and horizontal mixing constants.

630 The forcing data collected from observations and ROMS simulation are used to perform offline 631 tests of EBM in the Columbia River estuary. The geometries of EBM box structures are 632 calculated basic on the GEBCO and Google Earth measurements. And the mixing parameters are 633 optimized with MATLAB intrinsic function. EBM results successfully represent seasonal 634 outflow salinity variations associated with river discharge variability and outflow volume fluxes. 635 The EBM is applied globally in POP2 for a CESM (sea-ice-ocean-only) run and compared to an 636 otherwise identical case without estuary processes and a case with settings typical of prior 637 studies. Comparisons indicate strong sensitivity to the treatment of rivers in CESM; there are 638 significant local, regional, and remote effects. The EBM now is included as an option in CESM 639 version 2. A future paper will compare CESM to an appropriate observational coastal 640 climatology and explore dynamical changes introduced by rivers.

\section{Acknowledgements}

643 We are indebted to Rich Garvine for inspiring this research. We thank Parker MacCready for 644 formative discussions throughout this research and thank the editor and anonymous reviewers for 
645 their many helpful comments. We also thank high-performance computing support from 646 Yellowstone (ark:/85065/d7wd3xhc) provided by NCAR's Computational and Information

647 Systems Laboratory, sponsored by the National Science Foundation. This work was supported by 648 the U.S. Department of Energy, Office of Biological and Environmental Research under grant 649 DE-SC0006814. FOB was supported by the National Science Foundation through its sponsorship 650 of NCAR.

651

652 Appendix

653 The tidal pumping of salt through the mouth upper-layer (represented as a horizontally diffusive 654 flux in subtidal analysis) is derived in this section. Stommel and Farmer (1952) propose that the 655 estuarine outflow into the ocean has a jet-like form during ebb tide and the inflow during flood is 656 entrained from a semi-circular zone. Thus, much of the water passing into the mouth is not the 657 same as the water that left the estuary during the preceding ebb. The net effect over a tidal cycle 658 is oceanic water near the estuarine mouth is pumped into the estuary and some freshwater is 659 ejected to the coastal ocean (Figure A1). Tidal pumping drives a tidally-averaged salt mass (and 660 salinity) flux and PE flux into estuary; it acts as a horizontal diffusive flux in the subtidal 661 balances. MacCready (2004) parameterizes the horizontal diffusivity at mouth of the estuaries 662 based on the tidal pumping concept. The EBM development also is parameterized by following 663 this idea and the flood entrainment region is generalized to a semi-ellipse that accommodates 664 both narrow mouths (previously considered) and wider mouths relative to the tidal excursion 665 (Figure A1). 
666 The tidal pumping derivation begins with specifying the jet-like water mass lost during ebb:

$667 \mathrm{M}_{\mathrm{ebb}}=\rho_{\mathrm{UM}} \mathrm{WL}_{\mathrm{t}}(\mathrm{H}-\mathrm{h})$. The water mass gained during flooding is: $\mathrm{M}_{\mathrm{flood}}=\left[\rho_{\mathrm{UM}}\left(\mathrm{WL}_{\mathrm{t}}-\right.\right.$ $\left.668 \mathrm{~A})+\rho_{\mathrm{LM}} \mathrm{A}\right](\mathrm{H}-\mathrm{h})$, where $\mathrm{L}_{\mathrm{t}}$ is the tidal excursion (specified below) and $\mathrm{A}$ is the non669 overlapping area between the ebb jet and flood inflow zone. For simplicity, it is assumed that the 670 oceanic inflow water (from the non-overlapping part of the flood inflow) has the same density as 671 the water through the lower layer mouth. Note that the tidal exchange volume $\mathrm{WL}_{t}(\mathrm{H}-\mathrm{h})$ is the 672 same for flood and ebb. The net mass change in one tidal cycle is: $\Delta \mathrm{M}=\mathrm{M}_{\mathrm{flood}}-\mathrm{M}_{\mathrm{ebb}}=$ $673 a_{t}\left(\rho_{L M}-\rho_{U M}\right) W L_{t}(H-h)$, with $a_{t}=A /\left(W L_{t}\right)$. The coefficient $a_{t}$ is the ratio of the non674 overlapping volume (of oceanic water) to the total ebb/flood exchange volume. The tidal 675 excursion $\left(\mathrm{L}_{t}\right)$ is defined in terms of the tidal current amplitude $\left(\mathrm{u}_{\mathrm{t}}\right)$ of the linear sinusoidal tidal 676 wave with tidal period $\mathrm{T}_{\mathrm{t}}(\mathrm{Eqn} . \mathrm{A} 1) ; \mathrm{L}_{\mathrm{t}}$ is the distance water moves out from the estuary on ebb.

$$
L_{t}=\int_{0}^{\frac{T_{t}}{2}} u_{t} \sin (\omega t) d t=\frac{T_{t}}{\pi} u_{t}
$$

677 The average volume flux magnitude during either flood or ebb is found by dividing the tidal 678 exchange volume by half the tidal period (Eqn. A2).

$$
\mathrm{Q}_{\mathrm{Ut}}=2 \frac{\mathrm{u}_{\mathrm{t}}}{\pi} \mathrm{W}(\mathrm{H}-\mathrm{h})
$$

679 Vertically and horizontally integrating the horizontal diffusion term in the continuous PE balance 680 (Eqn. 4), applying the no-diffusive-flux conditions at the head and lower-layer at the mouth, and 681 representing the upper-layer horizontal density gradient as $a_{0}\left(\rho_{L M}-\rho_{U M}\right) / L_{t}$ gives the 682 horizontal diffusive mass flux (Eqn. A3).

$$
\begin{array}{rlrl}
\int_{-\mathrm{L}}^{0} \int_{0}^{\mathrm{H}} \frac{\partial}{\partial \mathrm{x}}\left[\mathrm{K}_{\mathrm{H}} \frac{\partial(\mathrm{PE})}{\partial \mathrm{x}}\right] \mathrm{dzdx} & =\frac{1}{2} \mathrm{~K}_{\mathrm{HM}} \frac{\rho_{\mathrm{LM}}-\rho_{\mathrm{UM}}}{\mathrm{L}_{\mathrm{t}}} \mathrm{g}\left(\mathrm{H}^{2}-\mathrm{h}^{2}\right) \\
& =\frac{1}{2} \mathrm{a}_{0} \mathrm{a}_{\mathrm{t}}\left(\rho_{\mathrm{LM}}-\rho_{\mathrm{UM}}\right) \frac{\mathrm{Q}_{\mathrm{Ut}}}{2 \mathrm{~W}} \mathrm{~g}(\mathrm{H}+\mathrm{h}) &
\end{array}
$$


683 The parameter $\mathrm{a}_{0}$ is introduced because of the approximation of the horizontal density gradient

684 at the estuary mouth. An analogous substitution is made for the horizontal diffusive flux in the 685 PE balance (Eqn. 7 and Eqn. 13). For completeness, the horizontal diffusivity is found in Eqn. 686 A4 by assuming the horizontal diffusion at the estuary mouth is due to net mass flux from tidal 687 pumping averaged over the entire tidal period.

$$
\mathrm{K}_{\mathrm{HM}}=\mathrm{a}_{0} \mathrm{a}_{\mathrm{t}} \frac{\mathrm{L}_{\mathrm{t}}^{2}}{\mathrm{~T}_{\mathrm{t}}}=\mathrm{a}_{0} \mathrm{a}_{\mathrm{t}} \frac{\mathrm{L}_{\mathrm{t}} \mathrm{u}_{\mathrm{t}}}{\pi}
$$

688 MacCready (2007) finds that horizontal diffusivity is overestimated by using Stommel and 689 Farmer (1952), so he gives a reduction factor by $\epsilon=0.1$. In the current development of the EBM, 690 the $\mathrm{a}_{0}$ is the corresponding free parameter. If the $\mathrm{a}_{0}$ bigger than 1 , it is reveals that the horizontal 691 density gradient at estuary mouth is sharper than $\left(\rho_{\mathrm{LM}}-\rho_{\mathrm{UM}}\right) / \mathrm{L}_{\mathrm{t}}$. The $\mathrm{a}_{\mathrm{t}}$ is the tidal pumping 692 geometric ratio for flood zone, which can vary from a semi-ellipse to a semicircle. The product 693 of the semi-major $\left(r_{1}\right)$ and semi-minor $\left(r_{2}\right)$ axes of the semi-ellipse that equals the flood jet area 694 is given by Eqn. A5.

$$
\mathrm{r}_{1} \mathrm{r}_{2}=\frac{2 W \mathrm{~L}_{\mathrm{t}}}{\pi}
$$

695 The solutions for each radius are given by Eqn. A6 and Eqn. A7.

$$
\begin{gathered}
r_{2}= \begin{cases}L_{t} & W>\pi L_{t} / 2 \\
\sqrt{2 \mathrm{WL}_{\mathrm{t}} / \pi} & \mathrm{W} \leq \pi \mathrm{L}_{\mathrm{t}} / 2\end{cases} \\
\mathrm{r}_{1}=\frac{2 \mathrm{WL}_{\mathrm{t}}}{\pi \mathrm{r}_{2}}
\end{gathered}
$$

696 The sector angle $\theta$ in all cases is defined in equation (Eqn. A8), where $r_{s}$ (Eqn. A9) is the radius 697 along sector angle $\theta$ (Figure A1).

$$
\theta=\sin ^{-1}\left(\frac{\mathrm{W}}{2 \mathrm{r}_{\mathrm{s}}}\right)
$$




$$
r_{\mathrm{s}}=\sqrt{\mathrm{L}_{\mathrm{T}}^{2}-\frac{\mathrm{W}^{2}}{4 \mathrm{r}_{2}^{2}}\left(\mathrm{~L}_{\mathrm{t}}^{2}-\mathrm{r}_{2}^{2}\right)}
$$

698 For the semi-elliptical (wide-mouth) case (Figure A1 b), the $a_{t}$ equation (Eqn. A10) involves the 699 semi-major axis $r_{2}$ (Eqn. A6), the sector angle $\theta$ (Eqn. A8) and the ellipse radius along the sector 700 angle $\left(r_{s}\right)$ calculated with equation (Eqn. A9):

$$
\begin{gathered}
a_{t}=1-\frac{2 F+\frac{W}{2} r_{s} \cdot \cos (\theta)}{W_{t}} \\
\text { with } F=\frac{L_{t} r_{2}}{2}\left\{\theta+\tan ^{-1}\left[\frac{\left(L_{t}-r_{2}\right) \cdot \sin (\pi-2 \theta)}{\left(L_{t}+r_{2}\right)+\left(L_{t}-r_{2}\right) \cdot \cos (\pi-2 \theta)}\right]\right\}
\end{gathered}
$$

701 For cases where the mouth is relatively narrow and/or tides are strong (Figure A1 a), the flood 702 zone becomes semicircular $\left(r_{1}=r_{2}=r_{S}\right)$ and the surface area ratio $a_{t}$ is calculated by equation 703 (Eqn. A11).

$$
a_{t}=1-\frac{\frac{2 W L_{t}}{\pi} \cdot \theta+\frac{W}{2} \sqrt{\frac{2 W L_{t}}{\pi}} \cdot \cos (\theta)}{W L_{t}}
$$

704 If the overlap area is simplified as a rectangular, then the $\mathrm{K}_{\mathrm{HM}}$ solution will be same as 705 MacCready (2004) employed. 
707

708

709

710

711

712

713

714

715

716

717

718

719

720

721

722

723

724

725

726

727

728

729

730

731

732

733

734

735

736

737

\section{Bibliography}

Barthem, R. B. \& Schwassmann, H. O., 1994. Amazon river influence on the seasonal displacement of the Salt Wedge in the Tocantins River Estuary, Brazil, 1983-1985. Museu Paraense Emilio Goeldi, 10(1), pp. 119-130.

Bone, D., Rodriguez, C. T. \& Chollett, I., 2011. Polychaeta Diversity in the Continental Shelf Off the Orinoco River Delta, Venezuela. Grillo, O. \& Venora, Volume G, pp. 87-97.

Burenkov, V. I. \& Vasil'kov, A. P., 1995. The influence of runo from land on the distribution of hydrologic characteristics of the Kara Sea. Oceanology, English Translation, 34(5), pp. 591-599.

Cauwet, G. \& Sidorov, I., 1996. The biogeochemistry of Lena River: organic carbon and nutrients distribution. Marine Chemistry, 53(3), pp. 211-227.

Coles, V. L. et al., 2013. The pathways and properties of the Amazon River Plume in the tropical North Atlantic Ocean. Journal of Geophysical Research: Oceans, 118(12), p. 6894-6913.

Dai, A. \& Trenberth, K. E., 2002. Estimates of freshwater discharge from continents: Latitudinal and seasonal variations. Journal of Hydrometeorology, 3(6), pp. 660-687.

Danabasoglu, G. et al., 2012. The CCSM4 Ocean Component. Journal of Climate, 25(5), pp. 1361-1389.

Durack, P. J., 2015. Ocean salinity and the global water cycle. Oceanography, 28(1), pp. 20-31.

Dyer, K. R., 1998. Estuaries: A Physical Introduction, 2nd Edition. s.I.:John Wiley \& Sons.

Egbert, G. D. \& Erofeeva, S. Y., 2002. Efficient inverse modeling of barotropic ocean tides. Journal of Atmospheric and Oceanic Technology, 19(2), pp. 183-204.

Eisma, D. \& Van Bennekom, J., 1978. The Zaire river and estuary and the Zaire outflow in the Atlantic Ocean. Netherlands Journal of Sea Research, 12(3-4), pp. 255-272.

Emmerton, C. A., Lesack, L. F. W. \& Vincent, W. F., 2008. Nutrient and organic matter patterns across the Mackenzie River, estuary and shelf during the seasonal recession of sea-ice. Journal of Marine Systems, 74(3), pp. 741-755.

Fossati, M. \& Piedra-Cueva, I., 2008. Numerical modelling of residual flow and salinity in the Rio de la Plata. Applied Mathematical Modelling, 32(6), pp. 1066-1086.

Garvine, R. W., McCarthy, R. K. \& Wong, K.-C., 1992. The Axial Salinity Distribution in the Delaware Estuary and its Weak Response to River Discharge. Estuarine, Coastal and Shelf Science, 35(2), pp. 157165.

Garvine, R. W. \& Whitney, M. M., 2006. An estuarine box model of freshwater delivery to the coastal ocean for use in climate models. Journal of Marine Research, 64(2), pp. 173-194. 
Georgiou, I. Y. \& Hanegan, K., 2013. Hydrodynamics and Salinity Modeling in the Lowermost Mississippi River and Delta. New Orleans, LA, Mississippi River Hydrodynamic and Delta Management Study (MRHDM) Meeting.

Geyer, R. W., 1995. Tide-induced mixing in the Amazon Frontal Zone. Journal of Geophysical Research: Oceans, 100(C2), pp. 2341-2353.

Geyer, R. W., 2010. Estuarine salinity structure and circulation. In: Contemporary issues in estuarine physics, transport and water quality. New York: Cambridge University Press, pp. 12-26.

Giddings, S. N. et al., 2014. Hindcasts of potential harmful algal bloom transport pathways on the Pacific Northwest coast. Journal of Geophysical Research: Oceans, 119(4), pp. 2439-2461.

Godin, G., 1972. The analysis of tides. Toronto, Buffalo: University of Toronto Press.

Griffies, S. M. et al., 2009. Coordinated Ocean-ice Reference Experiments (COREs). Ocean Modelling, 26(1), pp. 1-46.

Griffies, S. M. et al., 2005. Formulation of an ocean model for global climate simulations. Ocean Science, $1(1)$, pp. 45-79.

Hansen, D. V. \& Rattray, M., 1966. New Dimensions in Estuary Classification. Limnology and Oceanography, 11(3), pp. 319-326.

Herzfeld, M., 2015. Methods for freshwater riverine input into regional ocean models. Ocean Modelling , Volume 90, pp. 1-15.

Hordoir, R., Polcher, J., Brun-Cottan, J. C. \& Madec, G., 2008. Towards a parametrization of river discharges into ocean general circulation models: a closure through energy conservation. Climate dynamics, 31(7-8), pp. 891-908.

Huijts, K. M. H., Schuttelaars, H. M., de Swart, H. E. \& Friedrichs, C. T., 2009. Analytical study of the transverse distribution of along-channel and transverse residual flows in tidal estuaries. Continental Shelf Research, 29(1), pp. 89-100.

lanniello, J. P., 1979. Tidally induced residual currents in estuaries of variable breadth and depth. Journal of Physical Oceanography, 9(5), pp. 962-974.

lanniello, J. P., 1981. Comments on tidally induced residual currents in estuaries: Dynamics and nearbottom flow characteristics. Journal of Physical Oceanography, 11(1), pp. 126-134.

Ingram, G. R. \& El-Sabh, M. I., 1990. Fronts and mesoscale features in the St. Lawrence estuary. In: Oceanography of a Large-Scale Estuarine System . New York: Springer, pp. 71-93.

IOC, IHO \& BODC, 2003. Centenary Edition of the GEBCO Digital Atlas, published on CD-ROM on behalf of the Intergovernmental Oceanographic Commission and the International Hydrographic Organization as part of the General Bathymetric Chart of the Oceans, Liverpool, U.K.: British Oceanographic Data Centre. 
Kravtsova, V. I., Mikhailov, V. N. \& Kidyaeva, V. M., 2009. Hydrological regime, morphological features and natural territorial complexes of the Irrawaddy River Delta (Myanmar). Water resources, 36(3), pp. 243-260.

Lagarias, J. C., Reeds, J. A., Wright, M. H. \& Wright, P. E., 1998. Convergence properties of the Nelder-Mead simplex method in low dimensions. SIAM Journal on optimization, 9(1), pp. 112-147.

Large, W. G. \& Yeager, S. G., 2009. The global climatology of an interannually varying air-sea flux data set. Climate Dynamics, 33(2-3), pp. 341-364.

MacCready, P., 1999. Estuarine Adjustment to Changes in River Flow and Tidal Mixing. Journal of Physical Oceanography, 29(4), pp. 708-726.

MacCready, P., 2004. Toward a unified theory of tidally-averaged estuarine salinity structure. Estuaries, 27(4), pp. 561-570.

MacCready, P., 2007. Estuarine adjustment. Journal of Physical Oceanography, 37(8), pp. 2133-2145.

MacCready, P., 2011. Calculating Estuarine Exchange Flow Using Isohaline Coordinates. Journal of Physical Oceanography, 41(6), pp. 1116-1124.

MacCready, P. \& Geyer, R. W., 2010. Advances in estuarine physics. Annual Review of Marine Science, Volume 2, pp. 35-58.

Nguyen, A. D., Savenije, H. H. G., Pham, D. N. \& Tang, D. T., 2008. Using salt intrusion measurements to determine the freshwater discharge distribution over the branches of a multi-channel estuary: The Mekong Delta case. Estuarine, Coastal and Shelf Science, 77(3), pp. 433-445.

Rahaman, H. et al., 2014. Development of a regional model for the North Indian Ocean. Ocean Modelling, Volume 75, pp. 1-19.

Rao, Y. R., 2005. Modelling of circulation and salinity in a tidal estuary. Journal of Coastal Research, Issue SI 42., pp. 363-369.

Rice, A. E., Whitney, M. M., Garvine, R. W. \& Huq, P., 2008. Energetics in Delaware Bay: Comparison of two box models with observations. Journal of Marine Research, 66(6), p. 873-898.

Saucier, F. J., Roy, F. \& Gilbert, D., 2003. Modeling the formation and circulation processes of water masses and sea ice in the Gulf of St. Lawrence, Canada. Journal of Geophysical Research, Oceans 108(C8).

Shevchenko, O. G. et al., 2013. Phytoplankton of the Amur River Estuary (Sea of Okhotsk) during the summer periods of 2005-2007. Russian Journal of Marine Biology, 39(2), pp. 92-106.

Simpson, J. H., Brown, J., Matthews, J. \& Allen, G., 1990. Tidal straining, density currents, and stirring in the control of estuarine stratification. Estuaries, 13(2), pp. 125-132.

Smith, R. et al., 2010. The Parallel Ocean Program (POP) Reference Manual. Rep. LAUR-01853. 
803 Stommel, H. M. \& Former, H. G., 1952. In: On the nature of estuarine circulation: part I (chapters 3 and 804 4). s.I.:Woods Hole Oceanographic Institution.

805 Tseng, Y.-H., Bryan, F. O. \& Whitney, M. M., 2016. Impacts of the representation of riverine freshwater 806 input in the community earth system model. Ocean Modelling, Volume 105, pp. 71-86.

807 Vinayachandran, P. N., Murty, V. S. N. \& Babu, V. R., 2002. Observations of barrier layer formation in the 808 Bay of Bengal during summer monsoon. Journal of Geophysical Research: Oceans (1978-2012, 107(C12), 809 pp. SRF-19.

810 Yin, J., Stouffer, R. J., Spelman, M. J. \& Griffies, S. M., 2010. Evaluating the uncertainty induced by the 811 virtual salt flux assumption in climate simulations and future projections. Journal of Climate, 23(1), pp. $81280-96$.

813 Zhang, E. et al., 2011. Analytical solution for salt intrusion in the Yangtze Estuary, China. Estuarine, 814 Coastal and Shelf Science, 91(4), pp. 492-501.

$815 \mathrm{Zu}, \mathrm{T}$. \& Gan, J., 2013. A numerical study of coupled estuary-shelf circulation around the Pearl River 816 Estuary during summer: Responses to variable winds, tides and river discharge. Deep Sea Research Part 817 II: Topical Studies in Oceanography, Volume 117, pp. 53-64.

818 Zweng, M. M. et al., 2013. World Ocean Atlas 2013, Volume 2: Salinity. In: S. Levitus \& M. A. Technical, 819 eds. NOAA Atlas NESDIS 74. s.I.:s.n., p. 39.

820 
Tables and Figures

824 Table 1 Columbia EBM test case settings

\begin{tabular}{|l|l|l|l|l|}
\hline EBM Runs & $\begin{array}{l}\text { Observations: } \\
\text { Spring-neap }\end{array}$ & $\begin{array}{l}\text { Observations: } \\
\text { No spring-neap }\end{array}$ & $\begin{array}{l}\text { ROMS: } \\
\text { Spring-neap }\end{array}$ & $\begin{array}{l}\text { ROMS: } \\
\text { No spring-neap }\end{array}$ \\
\hline $\mathbf{H}, \mathbf{h}(\mathbf{m})$ & $10.93,5.47$ & $10.93,5.47$ & $10.93,5.47$ & $10.93,5.47$ \\
\hline $\mathbf{W}(\mathbf{k m})$ & 3.67 & 3.67 & 3.67 & 3.67 \\
\hline River forcing & Daily USGS $\mathrm{Q}_{\mathrm{R}}$ & Filtered Daily USGS $\mathrm{Q}_{\mathrm{R}}$ & Daily ROMS $\mathrm{Q}_{\mathrm{R}}$ & Filtered Daily ROMS $\mathrm{Q}_{\mathrm{R}}$ \\
\hline Tidal forcing & Daily NOAA $\mathrm{u}_{\mathrm{t}}$ & $\mathrm{u}_{\mathrm{t}}=0.96\left(\mathrm{~m} \mathrm{~s}^{-1}\right)$ & Daily NOAA $_{\mathrm{t}}$ & $\mathrm{u}_{\mathrm{t}}=0.96\left(\mathrm{~m} \mathrm{~s}^{-1}\right)$ \\
\hline $\mathbf{S}_{\mathrm{LM}}(\mathbf{P S U})$ & 32 & 32 & ROMS $_{\mathrm{LM}}$ & Filtered ROMS $\mathrm{S}_{\mathrm{LM}}$ \\
\hline Coefficients & $\mathrm{a}_{0}=1.2, \mathrm{a}_{1}=0.93$ & $\mathrm{a}_{2}=0.7, \mathrm{a}_{1}=0.93$ & $\mathrm{a}_{0}=1.2, \mathrm{a}_{1}=0.93$ & $\mathrm{a}_{2}=0.7, \mathrm{a}_{1}=0.93$ \\
\hline $\mathbf{a 0} *$ at $=$ & $1.2 *($ varying at $)=$ & $1.2 * 0.59=$ & $1.2 *($ varying at $)=$ & $1.2 * 0.59=$ \\
a2 & $($ varying a2 $)$ & 0.7 & (varying a2 $)$ & 0.7 \\
\hline Comparison & Daily NOAA $\mathrm{S}_{\mathrm{UM}}$ & Filtered NOAA $\mathrm{S}_{\mathrm{UM}}$ & ROMS $\mathrm{S}_{\mathrm{UM}}, \mathrm{Q}_{\mathrm{UM}}$ & ROMS $\mathrm{S}_{\mathrm{UM}}, \mathrm{Q}_{\mathrm{UM}}$ \\
\hline
\end{tabular}

827 Table 2 EBM parameters for top 20 rivers in POP2 of CESM, where $\mathrm{W}$ is the width, $\mathrm{H}$ is the 828 height and $h_{*}$ is the layer depth $\operatorname{ratio}(\mathrm{h} / \mathrm{H})$ for the box dimensions. The $\mathrm{a}_{1}$ and $\mathrm{a}_{2}$ are the 829 dimensionless coefficients for vertical mixing and tidal pumping in the EBM.

\begin{tabular}{|l|c|c|c|c|c|l|}
\hline River Name & $\mathrm{W}(\mathrm{m})$ & $\mathrm{H}(\mathrm{m})$ & $\mathrm{h}_{*}(-)$ & $\mathrm{a}_{1}(-)$ & $\mathrm{a}_{2}(-)$ & References to get annual mean $\mathrm{S}_{\mathrm{UM}}$ \\
\hline \hline Amazon & 50000 & 21.8 & 0.5 & 1.00 & 0 & Geyer (1995) \\
\hline Congo & 9740 & 8.0 & 0.5 & 1.04 & 2.57 & Eisma and Van Bennekom (1978) \\
\hline Orinoco & 17000 & 10.0 & 0.5 & 1.52 & 0 & Bone et. al. (2011) \\
\hline Changjiang & 28870 & 7.4 & 0.5 & 1.59 & 0 & Zhang et al. (2011) \\
\hline Brahmaputra & 11000 & 14.0 & 0.5 & 0.16 & 0 & Rao (2005) \\
\hline Mississippi & 4000 & 12.0 & 0.5 & 1.07 & 3.84 & Georgiou and Hanegan (presentation) \\
\hline Yenisey & 61500 & 3.8 & 0.5 & 1.29 & 0 & Burenkov and Vasil'kov (1995) \\
\hline Parana & 30000 & 7.5 & 0.5 & 0.58 & 0 & Fossati and Piedra-Cueva (2008) \\
\hline Lena & 5800 & 9.3 & 0.5 & 0.11 & 0 & Cauwet and Sidorov (1996) \\
\hline Mekong & 15200 & 6.5 & 0.5 & 1.13 & 0.89 & Nguyen and Savenije (2006) \\
\hline Tocantins & 62000 & 16.0 & 0.5 & 0.03 & 0 & Barthem and Schwassmann (1994) \\
\hline Ob & 47270 & 8.6 & 0.5 & 0.02 & 0 & Burenkov and Vasil'kov (1995) \\
\hline Ganges & 9000 & 14.0 & 0.5 & 0.05 & 0 & Rao (2005) \\
\hline Irrawaddy & 35140 & 22.5 & 0.5 & 0.15 & 0 & Kravtsova et al. (2009) \\
\hline St. Lawrence & 4680 & 42.9 & 0.5 & 1.03 & 2.57 & Ingram and Ei-Sabh (1990) \\
\hline Amur & 20000 & 14.3 & 0.5 & 0.11 & 0 & Shevchenko et al. (2013) \\
\hline Mackenzie & 25000 & 2.8 & 0.5 & 1.16 & 0.51 & Emmerton et al. (2008) \\
\hline Xijiang & 29000 & 5.2 & 0.5 & 0.28 & 0 & Zu and Gan (2015) \\
\hline Columbia & 3670 & 10.9 & 0.5 & 1.10 & 1.08 & NOAA buoy jtaw1 \\
\hline UNIFORM & 2000 & 10.0 & 0.5 & 0.88 & 0 & Geyer (2010) \\
\hline
\end{tabular}




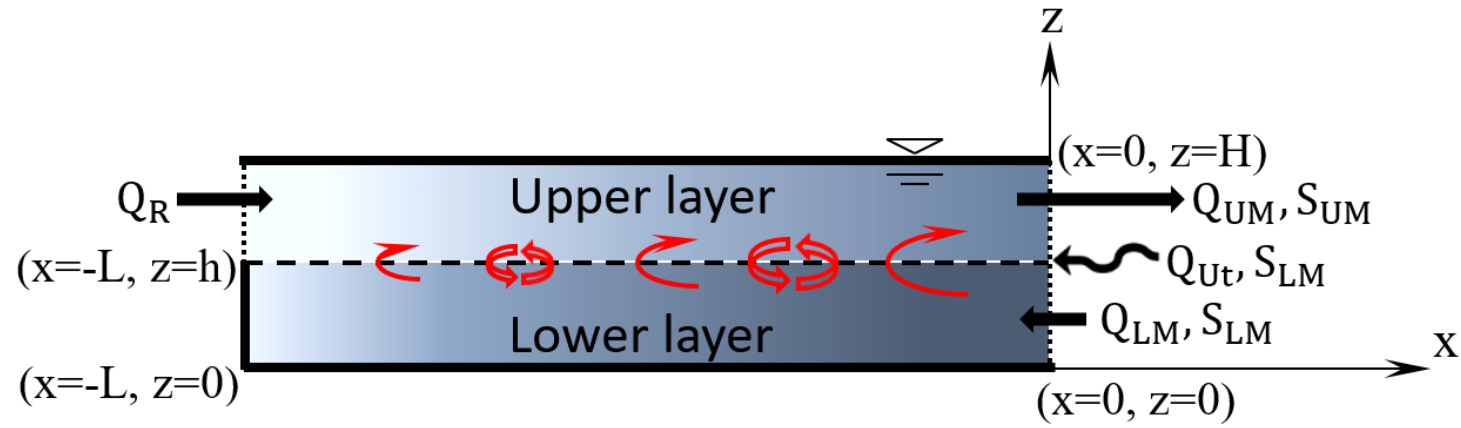

832 Figure 1 Schematic representation of the EBM. Thick solid lines indicate closed boundaries, 833 dotted lines show open boundaries, and the dashed line is the layer interface. Volume fluxes 834 along with salinities are represented with arrows at open boundaries. Shear induced turbulent 835 mixing (coupled upward and downward open arrows) and the upward advection associated with 836 exchange flow (upward solid arrows) connect the upper and lower layers. The color gradient 837 represents salinity variations from fresher (lighter shades) to saltier (darker shades) waters. 


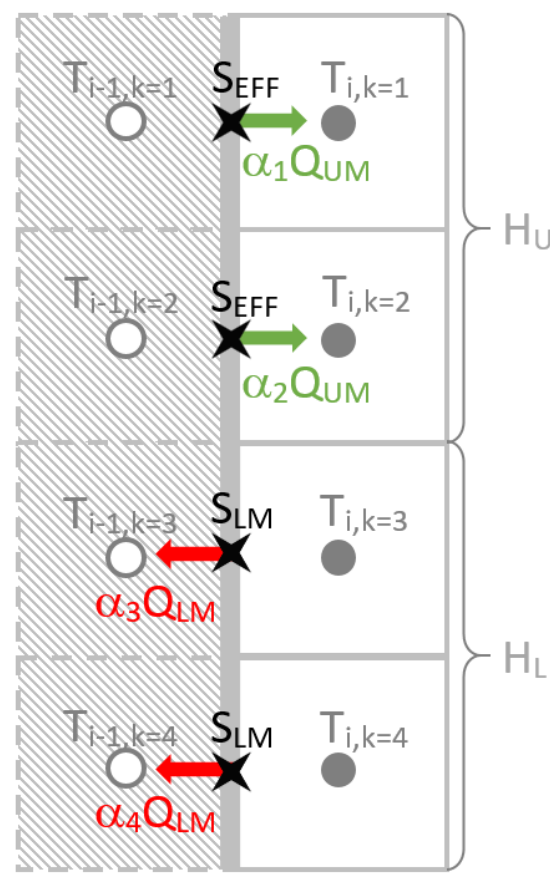

(a)
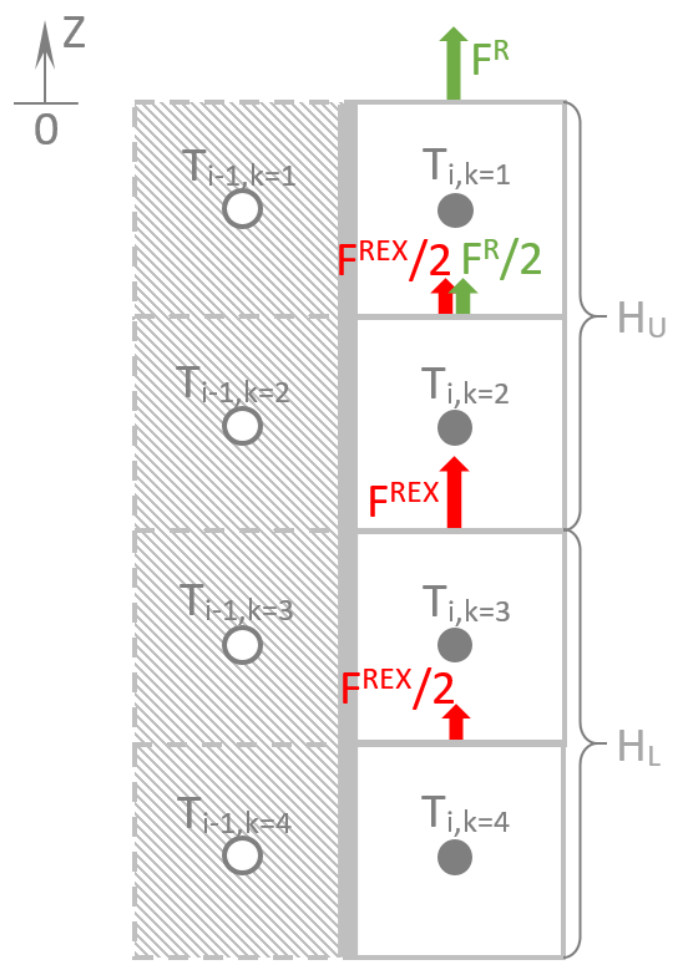

(b)

Figure 2 Schematic representation of EBM implementations for the climate ocean models with a) real boundary fluxes treatment and b) virtual salt fluxes treatment. The solid or dashed lines bounded boxes are the typical numerical grid cells with tracer point " $T$ " in the middle. The shaded grid cells are on land and the thicker solid lines show the vertical ocean-land boundaries. The colored arrows indicate the volume fluxes in (a) and virtual salt fluxes in (b) cross the grid faces, and the 4-points stars are located where the salinity values given by EBM. The $\mathbf{H}_{\mathbf{U}}$ and $\mathbf{H}_{\mathbf{L}}$ show the upper and lower layer thicknesses in POP2. The values of VSF $\left(\mathbf{F}^{\mathbf{R}}\right.$ and $\left.\mathbf{F}^{\mathbf{R E X}}\right)$ on the grid cell interfaces shown in the (b) are practically for the POP2 with equal $\mathbf{d Z}_{\mathbf{k}}$.

.




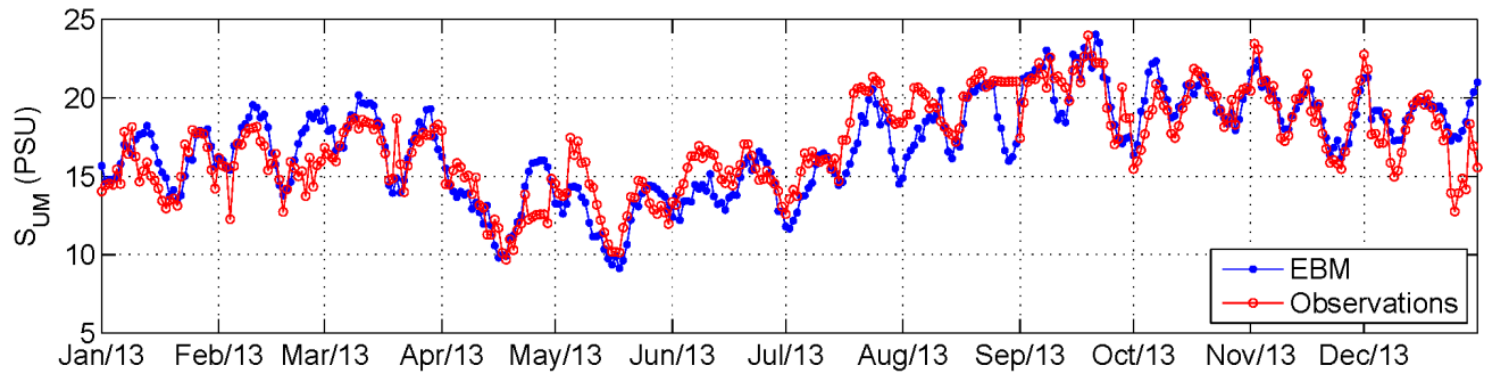

(b)

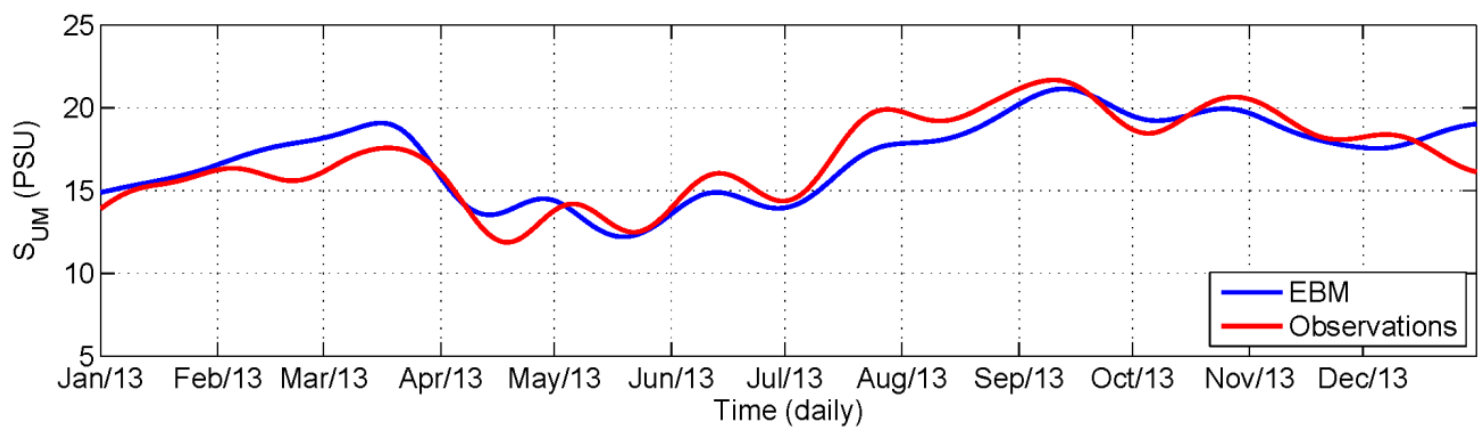

871

872 Figure 3 Comparisons of daily mean outflow salinity given by the EBM (blue) and observations

873 (red) for 2013 at the Columbia River mouth. (a) With the spring-neap $Q_{r}$ and $u_{t}$ and (b) without 874 spring-neap tidal variations.

875

876

877

878

879

880

881

882

883

884

885

886

887 
(a)
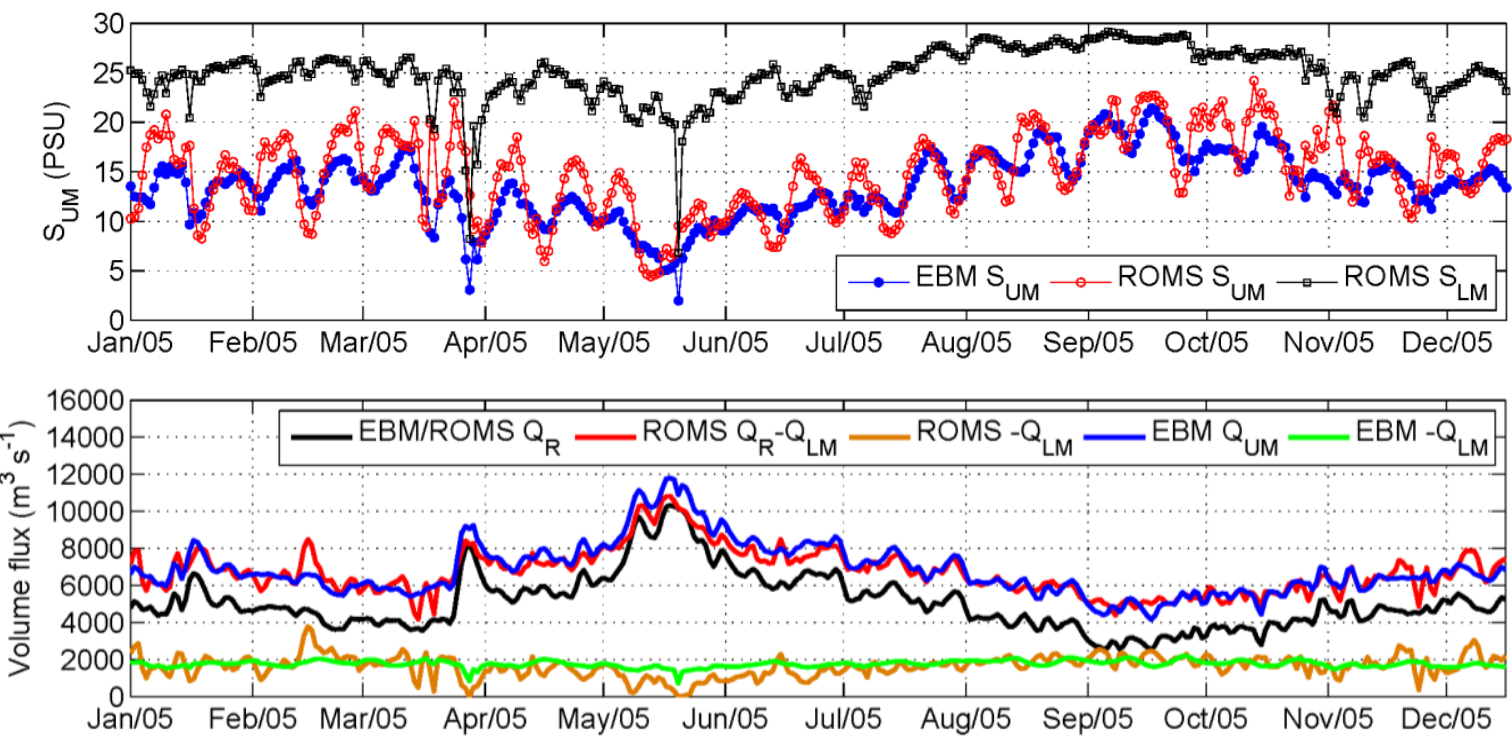

(c)
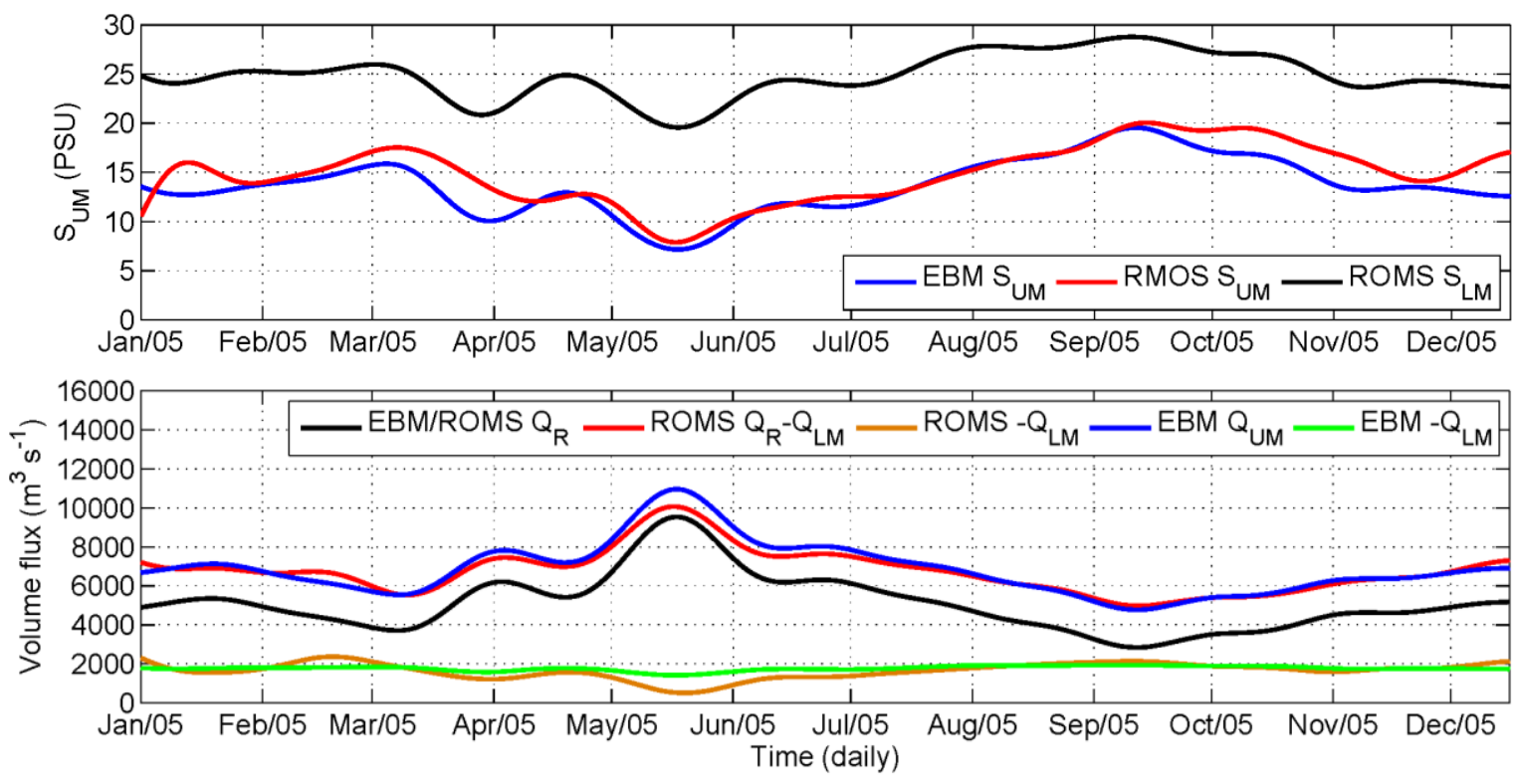

892 Figure 4 Columbia River estuary comparisons between the EBM solution and the ROMS simulation. (a) and (b) compare salinity and volume fluxes with spring-neap tidal variations included. (c) and (d) compare salinity and volume fluxes without spring-neap tidal variability. 
909

910

911

912

913

914

915

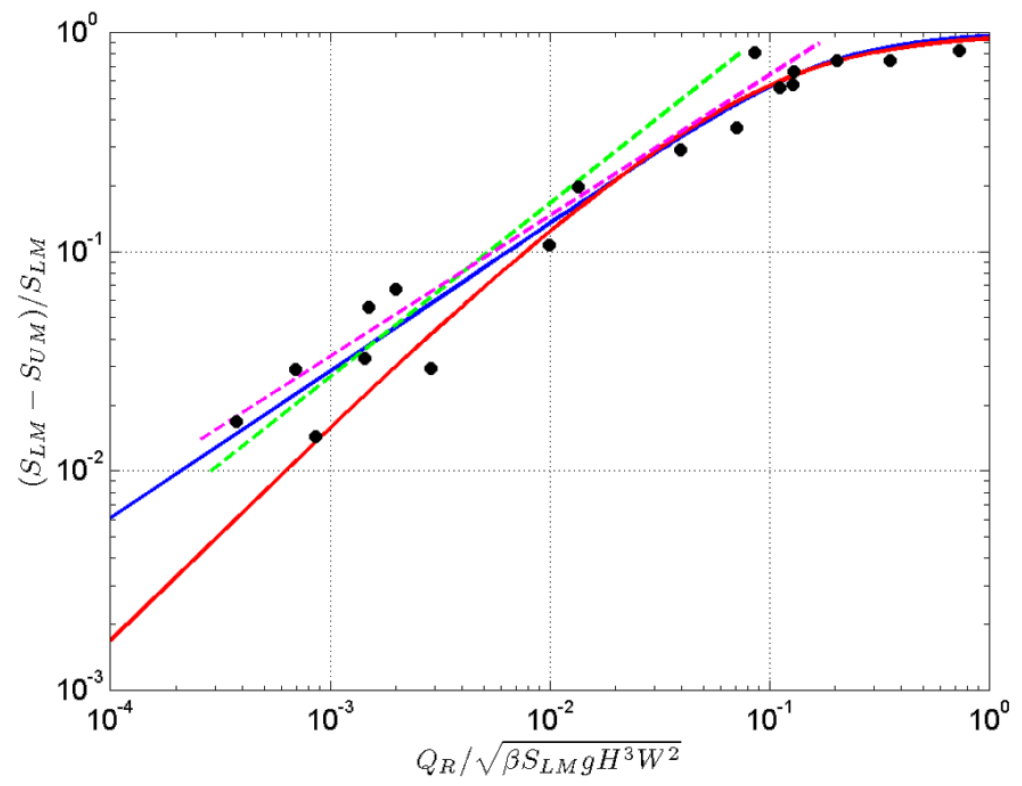

Figure 5 Scaled stratification at estuary mouths vs. scaled river discharge (a densimetric Froude number). Black dots are observations in 13 estuaries regenerated from Geyer (2010). Dashed lines are Geyer's solutions considering tides (green) and neglecting tides (magenta). Solid (blue and red) lines are the solutions of EBM. The blue line shows the tidal pumping neglected EBM with $\mathrm{a}_{1}=0.876$, which gives a RMSE of 0.086 and R-squared of 0.93 to the observations. And the red line with tidal amplitude of 1 meter to force the tidal pumping and the mixing parameters $\mathrm{a}_{1}=0.200, \mathrm{a}_{2}=0.285$, which gives a RMSE of 0.082 and R-squared of 0.94 . 
(a)

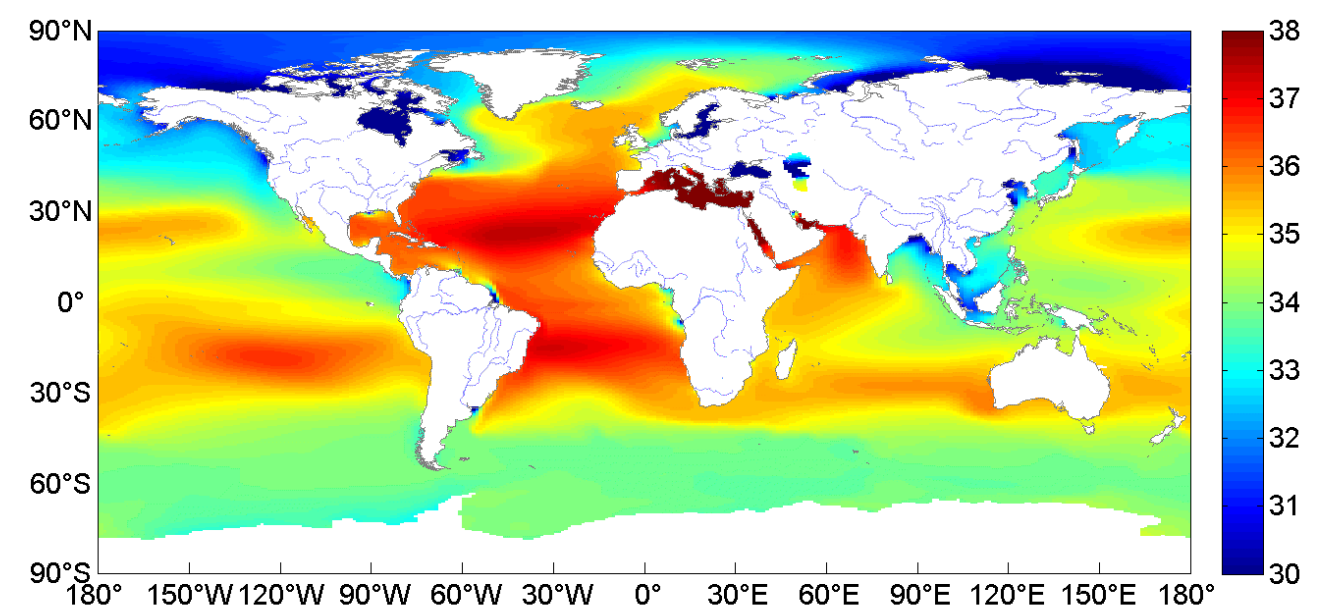

(b)

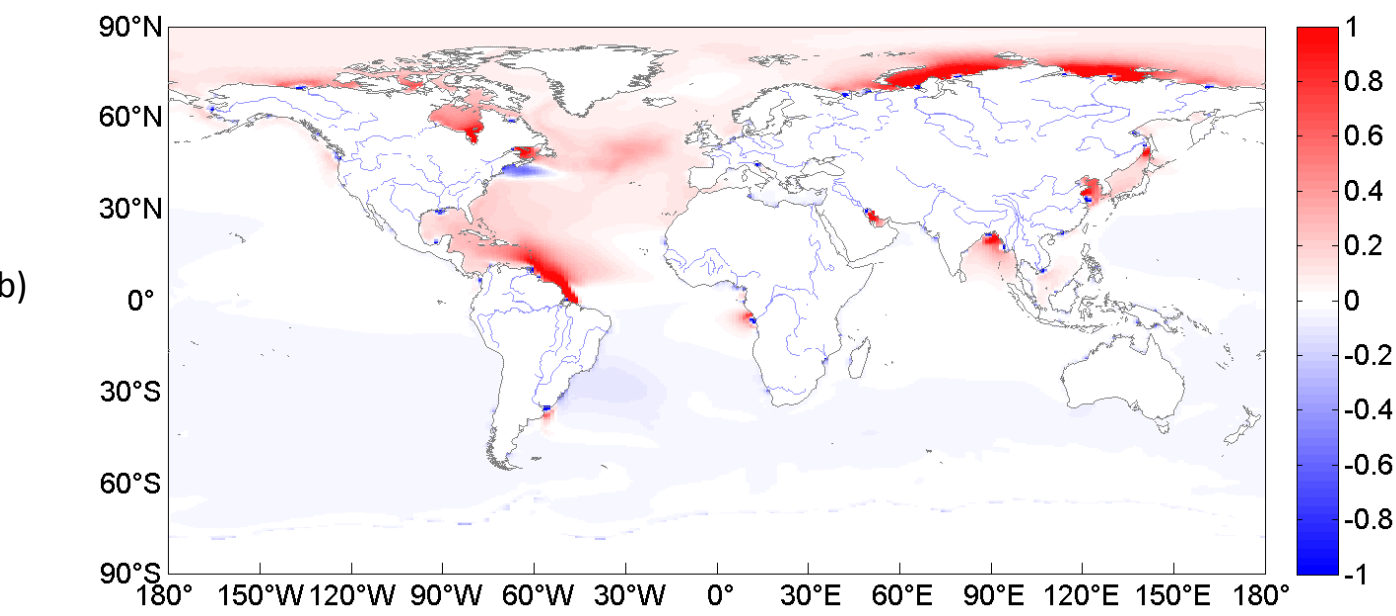

(c)

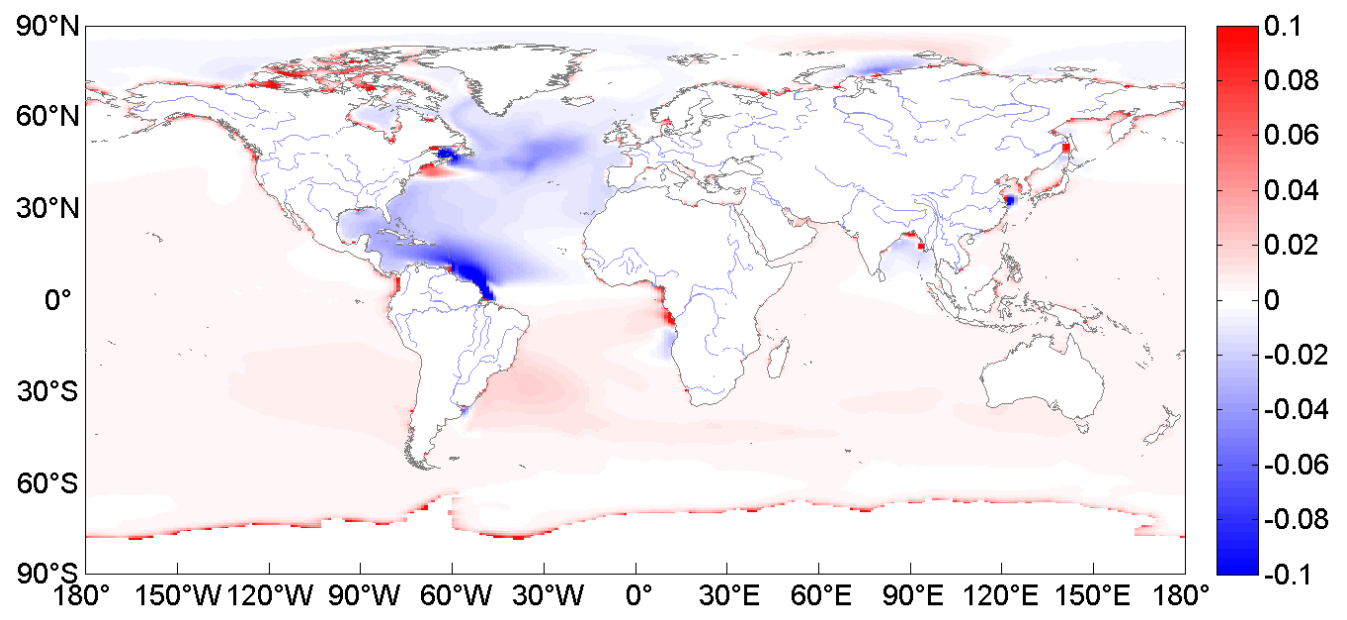

919 Figure 6 (a) Sea surface salinity (SSS) of the VSFEBM case averaged over the last 30-year 920 simulation period. The cyan lines show the global major rivers from the World Data Bank II. (b) 921 SSS differences (VSFEBM - VSFSPRD) and (c) SSS differences (VSFEBM - VSFROF) over 922 the same period. 


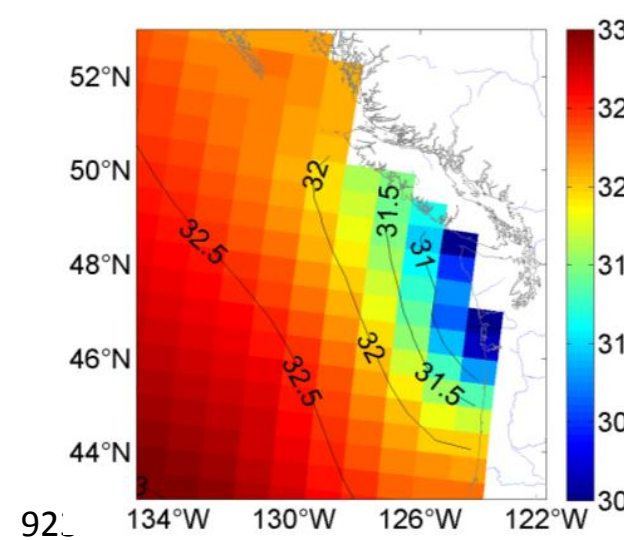

(a)

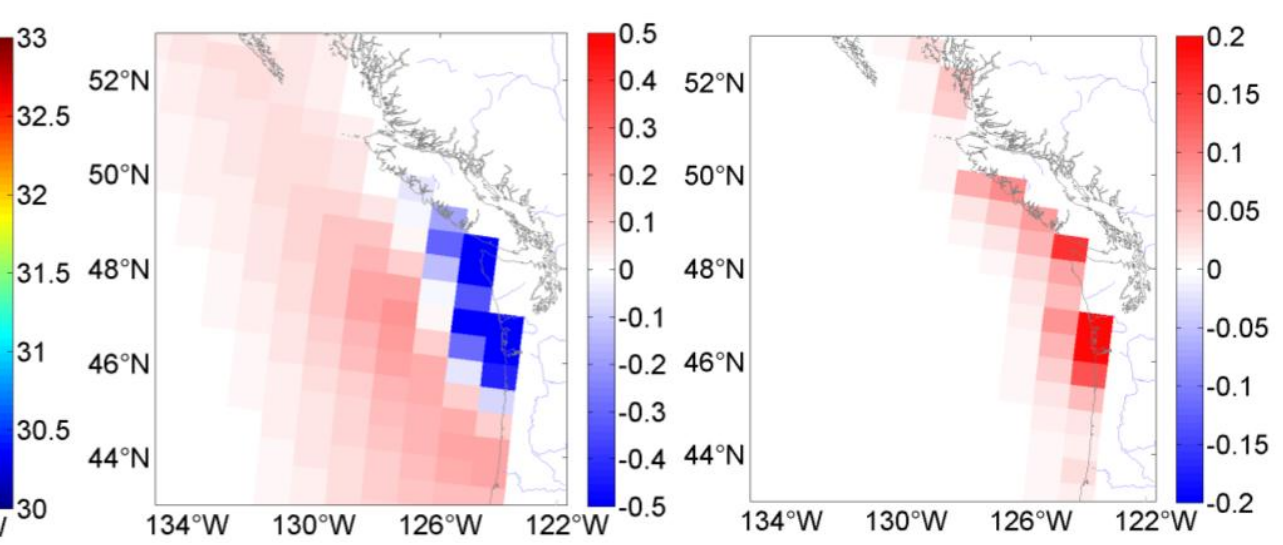

(b)

(c)

924

92

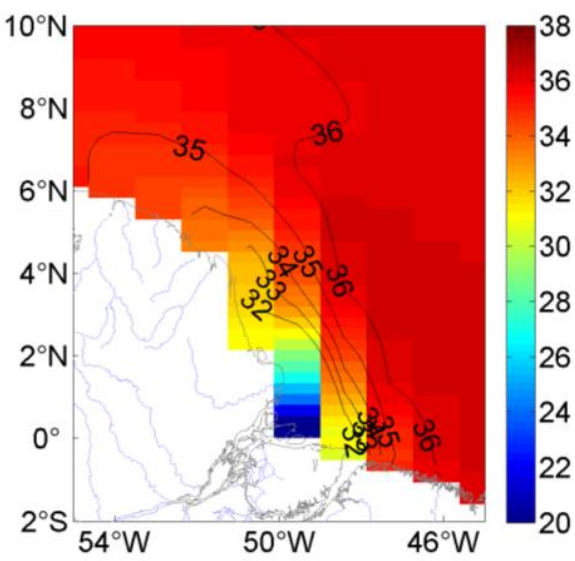

(d)

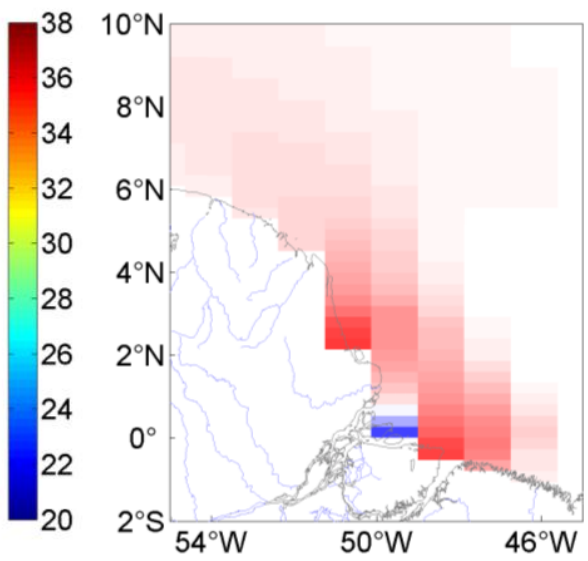

(e)
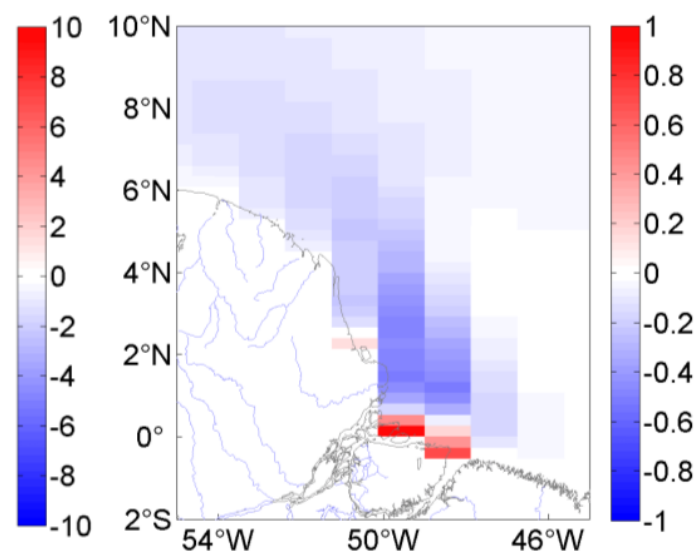

(f)

926

927 Figure 7 SSS in the VSFEBM case around the (a) Columbia and (d) Amazon River mouths. SSS 928 differences (VSFEBM - VSFSPRD) around the (b) Columbia and (e) Amazon River mouths. 929 SSS differences (VSFEBM - VSFROF) around the (c) Columbia and (f) Amazon River mouths. 


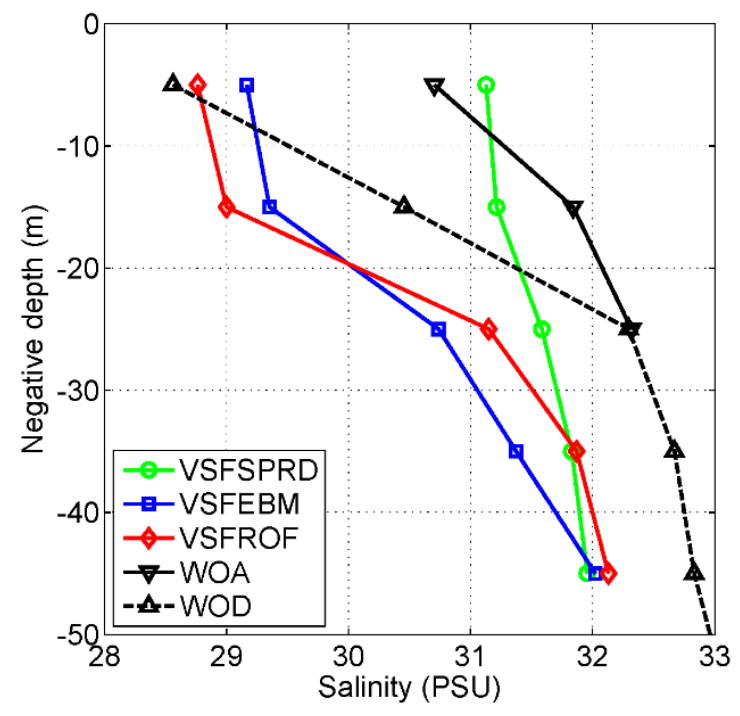

(a)

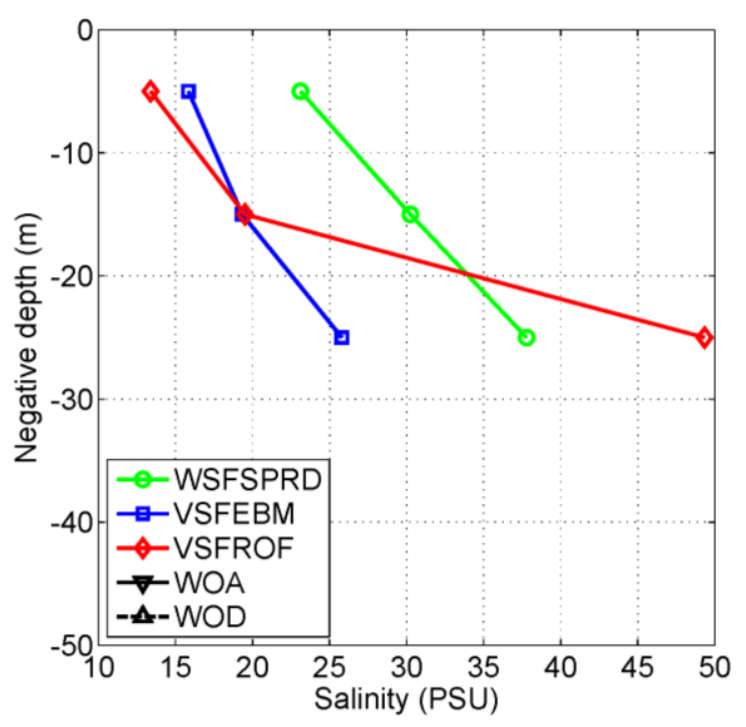

(b)

937 Figure 8 Vertical salinity profiles at the (a) Columbia River mouth $\left(123.96^{\circ} \mathrm{W}, 46.76^{\circ} \mathrm{N}\right)$ and (b) 938 Amazon River mouth $\left(49.56^{\circ} \mathrm{W}, 0.13^{\circ} \mathrm{N}\right)$ in POP2 for the VSFSPRD (circles), VSFEBM 939 (squares), and VSFROF (diamonds) cases. The black triangles show the annual mean 940 climatology data. The downward triangles are from the nearest WOA13 0.25 -degree salinity to 941 the POP2 T-grid, and the upward triangles are the POP2 T-grid cell averaged native WOD13 942 salinity. No WOA13 or WOD13 data are available at the Amazon mouth location. 

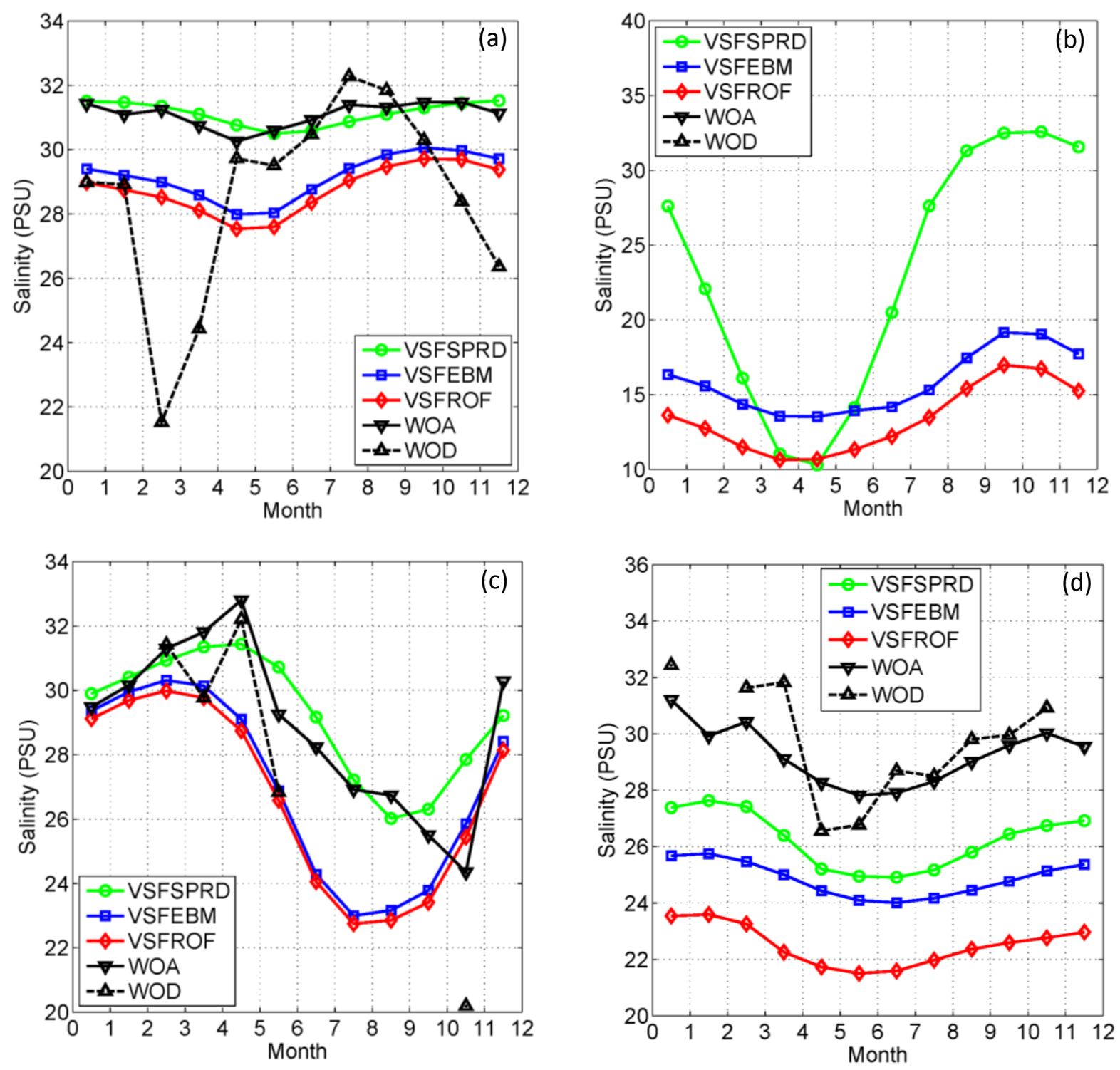

Figure 930 -year averaged surface salinity seasonal cycle at (a) Columbia $\left(123.96^{\circ} \mathrm{W}, 46.76^{\circ} \mathrm{N}\right)$, (b) Amazon $\left(49.56^{\circ} \mathrm{W}, 0.13^{\circ} \mathrm{N}\right)$, (c) Brahmaputra $\left(89.84^{\circ} \mathrm{E}, 21.58^{\circ} \mathrm{N}\right)$, and (d) St. Lawrence $\left(67.11^{\circ} \mathrm{W}, 49.41^{\circ} \mathrm{N}\right)$ River mouths in POP2. The black triangles show the annual mean climatology data. Coincident WOA13 and WOD13 salinities are shown with black downward and upward triangles, respectively (as in Figure 8). 


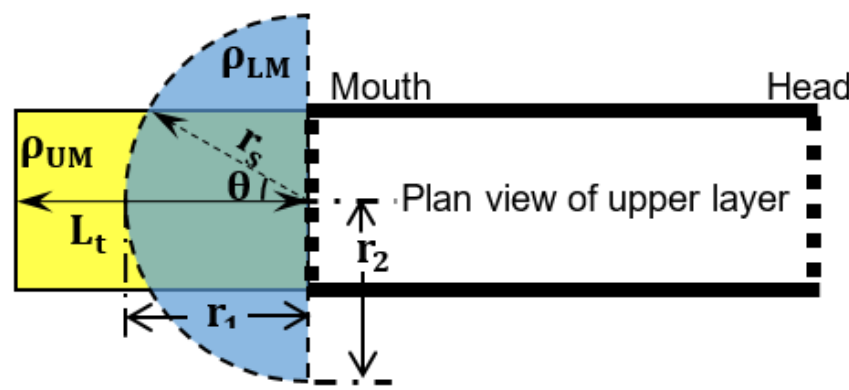

(a)

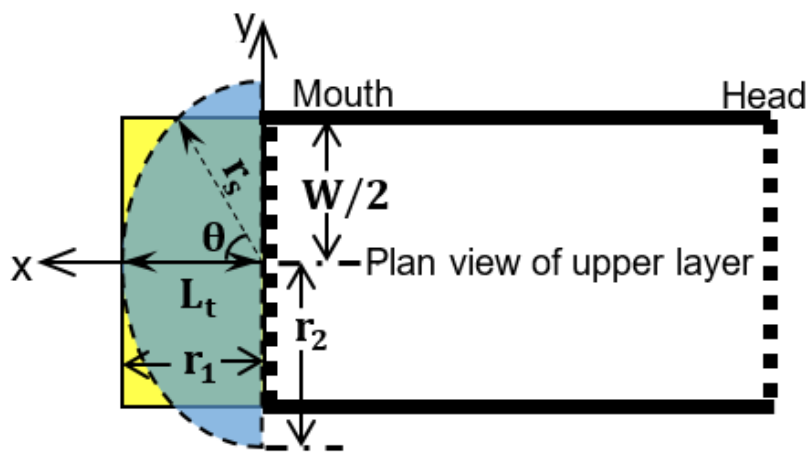

(b)

967 Figure A1 Schematic representation of tidal pumping effects in EBM upper layer for estuaries 968 with (a) a narrow mouth and/or strong tides and (b) a wide mouth and/or weak tides. The yellow 969 shade indicates the water released during ebbs and the blue shade shows the oceanic inflow 970 water during floods (the green shade indicates the overlap region). The ebb and flood regions 971 have the same water volume. The parameters marked with arrows are described in the appendix. 